\title{
A Synthesis Analysis of the Approach to Warm-up in Athletics and Music
}

\author{
by \\ Nona Ahmadi \\ A thesis submitted to the \\ Faculty of Graduate and Postdoctoral Affairs \\ in partial fulfillment of the requirements for the degree of
}

Master of Applied Science in Mechanical Engineering

Ottawa-Carleton Institute for Mechanical and Aerospace Engineering

Department of Mechanical and Aerospace Engineering

Carleton University

Ottawa, Ontario

March 2011

(C)Copyright

Nona Ahmadi, 2011 
Library and Archives Canada

Published Heritage Branch

395 Wellington Street Ottawa ON K1A ON4 Canada
Bibliothèque et

Archives Canada

Direction du

Patrimoine de l'édition

395 , rue Wellington

Ottawa ON K1A ON4

Canada
Your file Votre référence

ISBN: 978-0-494-81671-4

Our file Notre référence

ISBN: 978-0-494-81671-4
NOTICE:

The author has granted a nonexclusive license allowing Library and Archives Canada to reproduce, publish, archive, preserve, conserve, communicate to the public by telecommunication or on the Internet, loan, distribute and sell theses worldwide, for commercial or noncommercial purposes, in microform, paper, electronic and/or any other formats.

The author retains copyright ownership and moral rights in this thesis. Neither the thesis nor substantial extracts from it may be printed or otherwise reproduced without the author's permission.
AVIS:

L'auteur a accordé une licence non exclusive permettant à la Bibliothèque et Archives Canada de reproduire, publier, archiver, sauvegarder, conserver, transmettre au public par télécommunication ou par l'Internet, prêter, distribuer et vendre des thèses partout dans le monde, à des fins commerciales ou autres, sur support microforme, papier, électronique et/ou autres formats.

L'auteur conserve la propriété du droit d'auteur et des droits moraux qui protège cette thèse. $\mathrm{Ni}$ la thèse ni des extraits substantiels de celle-ci ne doivent être imprimés ou autrement reproduits sans son autorisation.
In compliance with the Canadian Privacy Act some supporting forms may have been removed from this thesis.

While these forms may be included in the document page count, their removal does not represent any loss of content from the thesis.
Conformément à la loi canadienne sur la protection de la vie privée, quelques formulaires secondaires ont été enlevés de cette thèse.

Bien que ces formulaires aient inclus dans la pagination, il n'y aura aucun contenu manquant. 
The undersigned hereby recommends to the

Faculty of Graduate and Postdoctoral Affairs

acceptance of the thesis

\title{
A Synthesis Analysis of the Approach to Warm-up in Athletics and Music
}

\author{
submitted by Nona Ahmadi \\ in partial fulfillment of the requirements for the degree of \\ Master of Applied Science in Mechanical Engineering
}

Professor M. Mc.Dill, Co-Supervisor

Professor D.Russell, Co-Supervisor

Professor Metin Yaras, Chair,

Department of Mechanical and Aerospace Engineering

Ottawa-Carleton Institute for Mechanical and Aerospace Engineering

Department of Mechanical and Aerospace Engineering

Carleton University

February, 2011 


\section{Abstract}

The expectation that warming up before physical activity reduces the risk of injury is widely accepted. While the potential value of warm-up appears to be generally understood, definitions of warm-up are neither consistent across disciplines nor within disciplines. While it is well-understood that warm-up reduces injury among athletes there is very little information on the definition or application of warm-up in the discipline of music, particularly as it applies to injury prevention.

A review of the literature relating to warm-up in athletics is presented. This allows the development of a novel framework for the definition of warm-up including passive warm-up, active warm-up and specific warm-up. Active warm-up has three components: aerobic exercise, stretching and repetition of movement. Specific warm-up has two components: repetition of movement and visualization. With the framework of the definition in place, a review of the limited and scattered information relating to warm-up in music is positioned within the now-defined framework of warm-up in athletics. A modification of the framework to accommodate the use of related movements in addition to repetition of movements is presented. A small data sample from music students regarding their attitudes toward warm-up was gathered and considered within the framework of the definition of warm-up in music.

A synthesis analysis of the definition and effects of warm-up for both disciplines is presented using qualitative and quantitative data. The synthesis analysis combined with the framework of the definition of warm-up, shows that musicians actually follow much of the methodology of warm-up demonstrated in athletics. Also, aerobic warmup, a normal component in athletics, is not a typical component of the warm-up routine in music. The role of aerobic exercise in athletics is well understood and it is recommended that light aerobic exercise may be equally beneficial in music, reducing the risk of injury and increasing the quality of the performance. 


\section{Acknowledgments}

I would like to acknowledge my supervisors Professor Moyra J. McDill and Professor Donald L. Russell for their support and encouragement. Their guidance and insightful comments inspired me a lot during my research work. I can not express enough my appreciation to my wonderful husband, Sina who has always been beside me with all his love and support. I also want to thank my lovely parents, brother and family-inlaw who encouraged and supported me emotionally throughout my studies. I would also like to thank my little son, Diyaco whose birth motivated me through the last stage of my research. 


\section{Table of Contents}

$\begin{array}{ll}\text { Abstract } & \text { iii }\end{array}$

Acknowledgments

Table of Contents $\quad$ v

List of Tables $\quad$ vii

List of Figures viii

1 Introduction 1

1.1 Introduction . . . . . . . . . . . . . . . . . 1

1.2 Warm- Ep Definition . . . . . . . . . . . . . 1

1.3 Physiological Effects of the Warm-Lp Routine . . . . . . . . . . 2

1.4 Psychological Effects of the Warm-Up Routine . . . . . . . . . . . 3

1.5 Problem Statement and Purpose of Study . . . . . . . . . . . 3

2 Physiological and Psychological Effects of Warm-Up on Athletes 5

2.1 Introduction . . . . . . . . . . . . . 5

2.2 Definitions of Warm-Up in Athletics . . . . . . . . . . . 5

2.3 Types of Athletic Warm-Up . . . . . . . . . . . . . . 6

2.4 Physiological and Psychological Aspects . . . . . . . . . . . 17

2.5 Warm-Up and Injury Prevention . . . . . . . . . . . . 18

3 Physiological and Psychological Effects of Warm-Up on Musicians 22

3.1 Introduction . . . . . . . . . . . . . . . . . . . . . . 22

3.2 Definitions of Warm-Up in Music . . . . . . . . . . . . . 23

3.3 Types of Music Warm-Up . . . . . . . . . . . . . . . . . . . . . 24 
3.4 Physiological and Psychological Aspects _. . . . . . . . . . 27

3.5 Warm-Up and Injury Prevention . . . . . . . . . . . . . 28

4 Warm-Up from the Perspective of Music Students 34

4.1 Informal Survey of the Attitude of Music Students . . . . . . . . . 34

4.2 Survey Results . . . . . . . . . . . . . . . . . . 42

5 Synthesis $\quad 44$

5.1 Introduction . . . . . . . . . . . . . . . . . . 44

5.2 Methods and Materials . . . . . . . . . . . . . . . . . 45

5.3 An Analysis of Published Opinions on Warm-Up . . . . . . . . 46

5.4 Synthesizing the Role of Warm-Up in Injury Prevention . . . . . . . 54

5.5 Summary . . . . . . . . . . . . . . . . . . 64

6 Contributions $\quad 66$

6.1 Discussion . . . . . . . . . . . . . . . . 66

6.2 Recomnendations...................... . . 67

6.3 Future Work. . . . . . . . . . . . . . . . . . . . . 68

$\begin{array}{ll}\text { List of References } & 69\end{array}$ 


\section{List of Tables}

5.1 Variation in Warm-Up Definitions . . . . . . . . . . . . . . 49

5.2 Effective Factors on Warm-Up Routine . . . . . . . . . . . 56

5.3 Warm-Up and Injury Prevention from Perspective of Athletes . . . 57

5.4 Injury Risk Factors from Perspective of Music Teachers . . . . . . . 59

5.5 Warm-Up and Injury Prevention from Perspective of Music Students 60

J.6 Time Spent by Music Teachers on Injury Prevention in a Lesson . . . 61

5.7 Injury Prevention Strategies from Perspective of 42 Music Teachers [1] 63

5.8 Treatments Offered by 105 Ausic Teachers . . . . . . . . . . . 64 


\section{List of Figures}

2.1 A Framework for the Definition of Warm-Up in Athletics . . . . . . 6

2.2 Passive Stretching . . . . . . . . . . . . . . . . . . . . . 9

2.3 Static Stretching . . . . . . . . . . . . . . . . . 10

2.4 Isometric Stretching . . . . . . . . . . . . . . . . 11

2.5 Ballistic Stretching . . . . . . . . . . . . . . . . 12

2.6 PNF Stretching . . . . . . . . . . . . . . . . . 13

2.7 Typical Viscoelastic Behavior of Muscle . . . . . . . . . . . . . 14

2.8 Sarcomeres . . . . . . . . . . . . . . . . . . 15

2.9 Cycle of Muscle Contraction . . . . . . . . . . . . . . . 20

3.1 A Framework for the Definition of Warm- $T^{\top} \mathrm{p}$ in Mnsic . . . . . . . . 24

3.2 Carpal Tumel . . . . . . . . . . . . . . . . . . 31

3.3 Focal Dystonia in the Right Hand . . . . . . . . . . . . . 32

3.4 Tendinitis . . . . . . . . . . . . . . . . 33

4.1 Forearm Stretching . . . . . . . . . . . . . . . . . 35

4.2 Arm Stretching . . . . . . . . . . . . . . . . . 35

4.3 Back Stretching . . . . . . . . . . . . . . . . . 36

4.4 Neck Stretching . . . . . . . . . . . . . . . . . . . 36

4.5 Stretching Described by Student A and Student F . . . . . . . 37

4.6 Finger Stretching Described by Student B . . . . . . . . . . . 38

4.7 Hand Stretching Described by Student B . . . . . . . . . . . . 38

4.8 Hand Stretching Described by Student C . . . . . . . . . . . . 39

4.9 Finger Stretching Described by Student C . . . . . . . . . . . 39

4.10 Stretching Described by Student G . . . . . . . . . . . . . 40

4.11 Hand Stretching Described by Student I . . . . . . . . . . . 41

4.12 Back Stretching Described by Student I . . . . . . . . . . . . . 42

5.1 A Framework for the Definition of Warm-Up and its Effects . . . . 47

5.2 Comparison of Warm-Up Types . . . . . . . . . . . . . . . 48 
5.3 Active Warm-Up Components: Musicians and Athletes . . . . . . . 52

5.4 Active Warm-Up Components: Musicians and Music Students . . . . 53

5.5 Specific Warm-Up Components: Musicians and Athletes . . . . . . 54

5.6 Specific Warm-Up Components: Musicians and Music Students . . . 55 


\section{Chapter 1}

\section{Introduction}

\section{$1.1 \quad$ Introduction}

The expectation that warming up before physical activity reduces the risk of injury is widely accepted. For example, the Arthritis Society of Canada recommends the following, [2] "Always be sure to stretch and warm-up before working in the garden. This will reduce stiffness and decreases your risk of injury." While the potential value of warm-up appears to be generally understood, definitions of warm-up are neither consistent across disciplines nor within disciplines. In general, warm-up refers to a period, prior to some specific physical activity, which prepares an individual in body and mind, for the event [3].

\subsection{Warm-Up Definition}

In the discipline of athletics, definitions of warm-up vary from author to author, but all carry a similar meaning. For example in Hedrick [4], warm-up is defined as "a perıod prior to performance which prepares an athlete physıologically and psychologically for athletic performance." Similarly, Roetert [5] defined warm-up as "low intensity exercise that elevates tissue temperature, increases heart rate and actively prepares the athlete for exercuse." Other authors $[3,6-8]$ have a range of definitions sharing similar ideas to that of Hedrick [4] and Roetert [5]. In contrast, warm-up is not well defined in the discipline of music and there is no clear definition of warm-up and its components. 
Warm-up can be categorized in different ways such as passive warm-up, active

warm-up sometimes called general warm-up, and specific warm-up [3,7,9-11]. In this interdisciplinary study, passive warm-up refers to increasing the temperature of a superficial part of the body by some external means; such as a hot shower, massage, or heating pads. Active warm-up refers to a period prior to exercise and it has three stages: exercising aerobically, stretching, and moving specific parts of body regarding to the subsequent event. Finally specific warm-up refers to a two stage preparation which includes movements that are related to the actual performance and visualization of the activity. More detail on warm-up in athletics is presented in Chapter 2.

In athletics it is widely but not universally accepted that warm-up prior to exercise decreases the risk of injury and improves performance $[1,6,7,12,13]$. Although there are different descriptions of warm-up routines, the available literature provides little information concerning the appropriate duration or the intensity of warm-up. Neuberger [1:3] stated that the intensity of the warm-up procedure is an important factor and attributed a vigorous warm-up to better physical performance when compared to moderate, short warm-ups. Depending on the type of sport, suggested warm-up routines can be different, i.e. some sports, such as tennis [11] may require more joint rotation while others such as running [ ;] may need more muscle stretching [16]. The range of injuries among musicians suggests there is incomplete understanding about the abilities of the human body and the applications of proper warm-up that could reduce the risk of injury.

\subsection{Physiological Effects of the Warm-Up Routine}

It has been reported $[7,11]$ that warm-up improves athletic performance and decreases the risk of injury by increasing muscle flexibility. As Taylor suggested [17], improvement in muscle flexibility is attributed to changes in the mechanical properties of the muscle. Active warm-up, or general warm-up, increases the muscle temperature and this elevation improves the range of motion $[6,18]$. It was suggested in [18] that a more flexible muscle-tendon unit is more able to sustain external loads and less likely to be injured. The observed increase in flexibility may be due to an increased stretch tolerance [19], or a change in mechanical properties of the muscle-tendon 
unit [17]. The mechanical properties of muscle-tendon units are viscoelastic in nature and are temperature dependent [20]. This temperature dependence can affect the tensile characteristics of the muscle [21]. This will be discussed in detail in Chapter 2 .

\subsection{Psychological Effects of the Warm-Up Routine}

Individuals can improve their performance by including psychological aspects in their warm-up routines $[22,23]$. Visualization improves self-confidence and concentration by repetitively previewing the upcoming activity in the mind. Moreover, visualization increases an individual's focus during the performance [6,24-26]. It has been stated that the physiological aspects of warm-up do not benefit an individual greatly if they are not accompanied by psychological preparation $[11,22]$.

\subsection{Problem Statement and Purpose of Study}

There are many different factors involved in injury in musicians. These include: improper techniques, poor posture, too much or too little practice, improper instrument size, emotional stress ${ }^{1}$ and lack of warm-up [2?]. Warm-up was seen to be one of the factors that has the potential to reduce the risk of injury and also to improve the quality of the performance. However, proper warm-up is not well defined in music. The purpose of this research is to study the physiological and the psychological effects of warm-up routines in athletics and correlate these to the warm-up routines in music. In this study, the effects of warm-up on the human body are first examined for athletes. These effects are not restricted to athletes and they may apply to musicians as well. In addition, this research emphasizes the combination of both physiological and psychological aspects of warm-up that may help improve the quality of playing as well as reduce the risk of injury. Finally this interdisciplinary study provides a novel framework for the definition for warm-up in the discipline of music.

In Chapter 2 a review of athletic warm-up is presented. It includes a discussion of different aspects of warm-up, different types of warm-up routines used and the

\footnotetext{
${ }^{1}$ Emotional stress refers to a state of being in which emotional factors, perhaps unrelated to music performance, result in the inability of the performer to play normally.
} 
beneficial effects of warm-up on athletes. A novel framework for the definition of warm-up is established. In Chapter 3, the available information and definitions of warm-up as understood by musicians are presented and the current factors that may be helpful for injury prevention are categorized. The framework for the definition of warm-up is then modified to accommodate the variations seen in music. Chapter 4 includes an informal survey about adolescent attitudes to warm-up. This step was considered in establishing the framework for musicians. In Chapter 5, a synthesis analysis is presented for warm-up in both disciplines. It is observed that, within the cstablished framework, musicians do not include the aerobic portion of warm-up. Finally the contributions of the thesis, including the discussion and recommendations along with suggestions for future work, are presented in Chapter 6. 


\section{Chapter 2}

\section{Physiological and Psychological Effects of Warm-Up on Athletes}

\section{$2.1 \quad$ Introduction}

It is common to see athletes warm-up prior to practice and performance. The expectations of this preparatory workout are improvement in the physical performance and a reduction in sport-related injuries $[0->, 2 y]$. While some studies $[20-31]$ have contradictory opinions about the benefits of warm-up for athletes; the main objection to warm-up surrounds the stretching component. For example, Shrier [29] presents five arguments against stretching. In this chapter, the definition of warm-up, its types and effects will be discussed. A framework for the definition of warm-up will be developed based on definition variations of warm-up and its effects in athletics.

\subsection{Definitions of Warm-Up in Athletics}

Warm-up is one of the most commonly recommended approaches to injury prevention [8] and it is suggested as a way to improve the performance of athletes [6-8]. It is useful to review several variations in the definition of warm-up. Frank [ 1 ] defined warm-up as "some form of moderate actıvity that athletes do before partıcipating in more strenuous exercise." Fradkin [8] defined warm-up as "some form of low intensity physical actıvty in training routınes before partıcipating in more strenuous exercise." Krista [3] defined warm-up as "a period pror to performance that is intended to decrease the chance of injury by improving muscle dynamics and also prepares athletes for the following performance." Marc [6] defined warm-up as "a way of preparing an 
athlete's mind, heart,lungs and muscles for athletic activities."

While many definitions exist, in this interdisciplinary study, a framework for warmup for athletics is defined as a period, prior to the event, in which one prepares the body and mind through three types of activities: passive warm-up, active warmup, and specific warm-up. Figure 2.1 shows a defined framework for athletics and its components as used in this thesis. Passive warm-up refers to increasing the superficial temperature in a part of body by some external means such as hot shower or massage. Active warm-up refers to a period prior to exercise and it has three stages: exercising aerobically, stretching, and repeating movements that are similar to the expected activity. Finally, specific warm-up refers to a two-stage preparation which includes movements that are related to the actual performance and visualization.

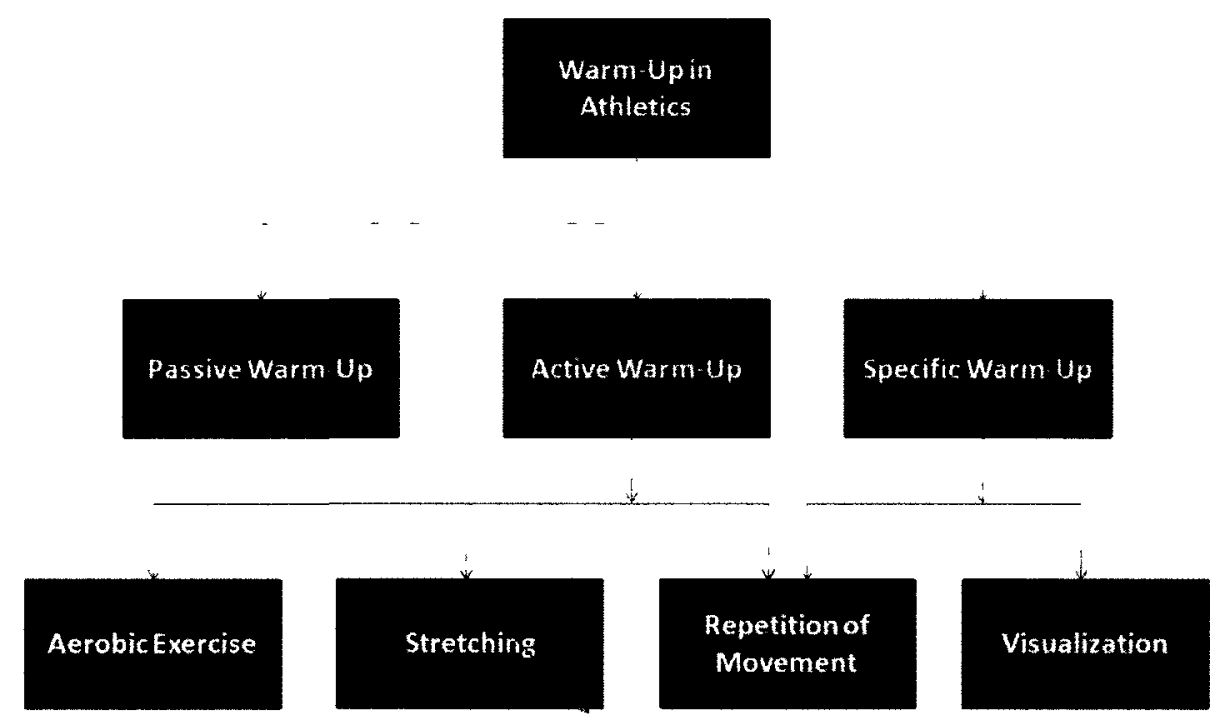

Figure 2.1: A Framework for the Definition of Warm-Up in Athletics

\subsection{Types of Athletic Warm-Up}

A more detailed discussion of the various forms of warm-up seen in athletes, is necessary if their use is to be considered for application in the discipline of music. 


\subsubsection{Passive Warm-Up}

Passive warm-up is a procedure that increases the superficial temperature of the skin and/or muscle by some external means, such as a hot shower, a steam bath, heating pads and massage $[3,5,7,9,11]$. Stricker [32] indicated that repetitive passive warm-up decreases tension in muscle-tendon units, which results in an increase of muscle tolerance towards tearing. Some studies [33-35] indicated that passive warmup prior to performance is beneficial and improves the athlete's performance by 1$26 \%$. Passive warm-up is not usually used alone but is often accompanied by active warm-up to get a better result [9].

\subsubsection{Active Warm-Up}

Active warm-up, also called general warm-up, is any non-specific body movement that causes the body temperature to rise $[3,6, \bar{i}, 9,36]$. It is the most common type of warm-up used among athletes due to its ability to change deep muscle temperature [:3]. Muscle movements in the aerobic phase increase the body temperature but they are not a forced or particular neuromuscular activity ${ }^{1}$ related to the subsequent event [20]. Jogging, jumping, stationary bicycle riding are typical examples of active warmup $[5, ! !]$. Perhaps, since active warm-up is not being restricted to any specific body movements, some literature refers to this as general warm-up. The active warm-up prepares one's body and mind through three stages: exercising aerobically, stretching the event-required muscles for the following event, and repetition of movements that are similar to the expected exercise. It appears that active warm-up is more common [?] than passive warm-up, since active warm-up increases muscle temperature, blood circulation, oxygen flow to the muscles and the mobilization of various hormones $[7,38]$. A description of these three stages will be given below.

\subsubsection{Aerobic Exercise}

Aerobic exercise is the first component of the active warm-up and is defined [39] as "brisk physical activity that requires the heart and lungs to work harder to meet the body's increased oxygen demand. Aerobic exercise promotes the circulation of oxygen through the blood." By performing aerobic exercise, working muscles require

\footnotetext{
${ }^{1}$ Neuromuscular activity refers to the activity that is pertained to both nerve and muscle of the particular part of body [37]
} 
more oxygen compared to muscles at rest. Consequently, the respiration rate and the heart rate increase and cardiovascular function increases. With an increase in cardiovascular function, the rate of blood flow to arteries increases; therefore, arteries dilate and consequently the resistance toward blood flow decreases. By increasing the blood flow, more oxygen is available to the working muscle and muscle temperature increases. The muscle metabolism increases by taking in more oxygen and giving out more waste. This, in turn, causes the hormonal balance to change which, in turn, enhances nervous system response, making the athletes more prepared for the subsequent activity. At the same time, the elevation in muscle temperature allows muscles to contract more rapidly and efficiently when compared to unwarmed muscles, which will lead to enhanced performance $[16,40,41]$. Hill [42] indicated that nerve receptors and the transmission speed of nervous impulses are sensitive to temperature. When the body temperature is slightly higher than normal, as it is during aerobic exercise, the response of the nervous system is enhanced. This enhanced nervous system function is very helpful in sports that demand complex movements of different parts of body [1:2]. Even though the temperature increase in muscle tissue during an aerobic exercise appears small, around $1.13^{\circ} \mathrm{C}$ [1:3], it can be enough to trigger hormonal and chemical reactions within the body.

\subsubsection{Stretching}

While stretching is usually defined as the second component of active warm-up routine, some references $[3,16,29,44]$ treat stretching separately. There does not appear to be a formal definition of stretching in the available literature. However, stretching is generally viewed to involve increasing muscle length and the range of motion of the associated joint(s) [45]. There are contradictory positions on the benefits of stretching. Howell [46] and Dean [47] recommended that stretching follows aerobic exercise as stretching improves the range of motion. Some $[20,48,49]$ mention that stretching improves the performance and reduces the risk of injury. Others [29, 16,50] state that stretching may increase the risk of injury. Furthermore, there are some $[51,52]$ who indicate that there is neither an advantage nor a disadvantage to stretching.

Stretching can be divided into a number of types: passive stretching, static stretching, isometric stretching, ballistic stretching, and propriatoceptive neuromuscular facilitation (PNF) [14]. Athletes may do one or more of the several stretching methods 
available, depending on the requirements of the sport. A brief description of the different types of stretching is presented below.

- Passive stretching, also called relaxed stretching, involves lengthening a muscle by a sustained stretch in a held position as shown in Figure 2.2. In passive stretching, the athlete often uses a partner to assist in maintaining the sustained hold [44].

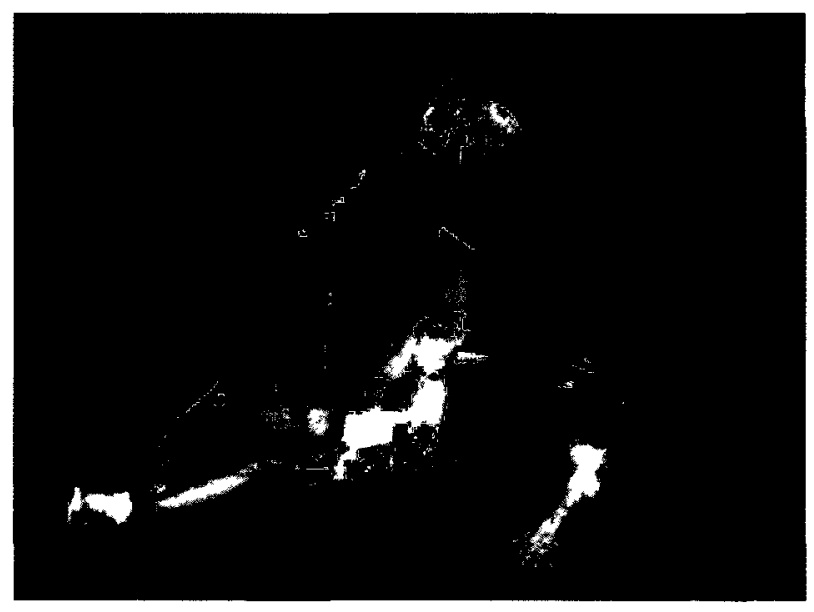

Figure 2.2: Passive Stretching [5;3]

- Static stretching is stretching a muscle to the point of discomfort and then holding the muscle at that situation for 15 to 60 seconds. Figure 2.3 shows static stretching. Athletes perform the static stretching on their own, without a partner [41].

- Isometric stretching is a variation of static stretching in which the lengthening muscle is held for 15 to 60 seconds using an immobile object such as a wall, as shown in Figure 2.4 [t4].

- Ballistic stretching involves repetitive bouncing motions, as shown in Figure 2.5. This is the oldest technique of stretching [44]. Craig et al. [16] do not recommend bouncing as a safe way of stretching due to creating more tension in the muscle. 


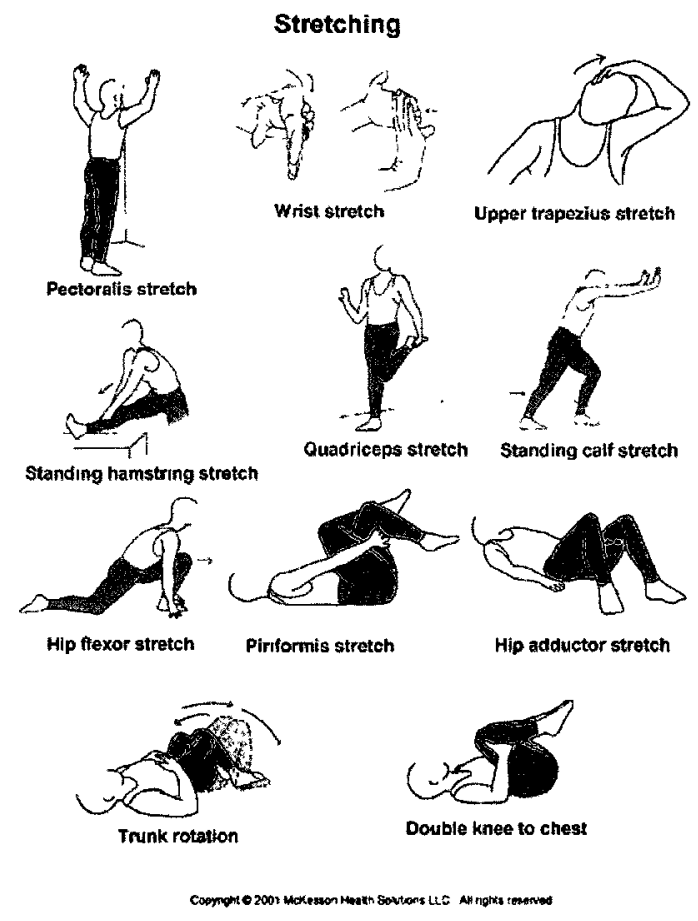

Figure 2.3: Static Stretching [:3]

- Proprioceptive Neuromuscular Facilitation, or PNF, combines passive stretching and isometric stretching [11]. PNF consists of a muscle being passively stretched, then contracted isometrically against the resistance while it is in the stretched position, as shown in Figure 2.6. This process is repeated several times while the required range of motion increases and is intended to improve flexibility [4t].

Flexibility is defined as [58], "the intrinsic property of the body tissues that determines the range of motion achievable without the injury at a joint or group of joints." There are two types of flexibility: static flexibility which refers to the degree to which a joint may be passively moved to the end points of the range of motion $[29,44,59]$, and dynamic flexibility which refers to the degree which a joint can be moved as a result of muscle contraction, usually passing through the midrange of movement. The dynamic range of motion is generally greater than static range of motion due to enhanced tissue elasticity and "reciprocal inhabitation" leading to relaxation of opposing muscles during physical activity [29, 44,59]. 


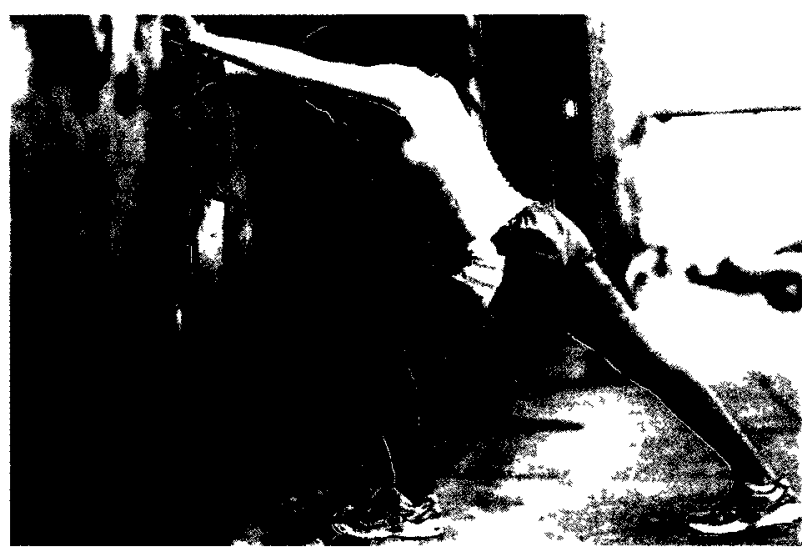

Figure 2.4: Isometric Stretching [55]

Proper stretching contributes to increasing the flexibility of joints [7]. A short-term increase in flexibility after stretching, can be attributed to: a decrease in muscletendon unit stiffness [ $[6]$; an increase in muscle tissue temperature [6]; and an increase in the muscle tolerance to stretching [29]. According to [60], an increase in flexibility through stretching decreases the incidence of muscle and tendon injuries and also diminishes muscle soreness and improves athletic performance $[6,-(i ;)$. Jones [ $6 i 1]$ stated that it is possible that too much or too little flexibility and in some cases increasing flexibility, may increase the risk of injury.

\subsubsection{To Stretch or Not to Stretch}

As indicated earlier, there is some debate over the value of warm-up, particularly as it applies to stretching. Given the explanation of flexibility, it is easier to understand this debate. Some studies, such as $[6,11,65]$ stated that stretching is beneficial for athletes by improving the performance and reducing the risk of injury. Others $[28,29]$ have argued that stretching may increase the risk of injury, these injuries may even occur during the stretching. This dilemma might be related to mechanical properties of muscle as a connective tissue. Muscle is strain rate sensitive [66] and its behavior will depend on the size of the applied load and the rate at which the load is applied. With momentary changes or elastic deformation, the muscle is able to return to its original length [67]. Permanent changes are such that a muscle is not able to return to its original length [67]. Viscoelastic changes in structure depend on duration and the rate at which the load is applied [17]. Typically, there is an initial elastic response 


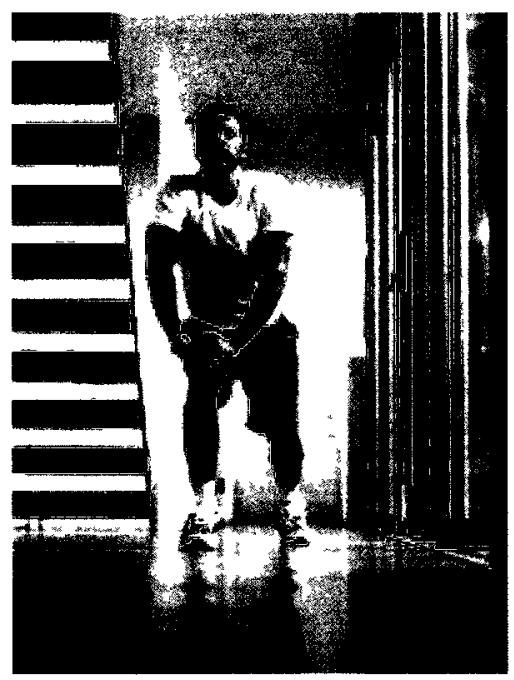

Figure 2.5: Ballistic Stretching [56]

followed by a viscous response, as shown in Figure 2.7. Stretching may involve elastic, plastic and viscoelastic responses in the muscle fiber. The duration and the amount of applied force influence the nature of the response [ $[i]$.

In [3'], Shrier presented five arguments refuting the value of stretching as a factor in injury reduction and performance improvement. His arguments relate to compliance of the muscle, whether active or passive, energy absorption, correct stretching techniques, and pain threshold of the athlete.

Shrier's [2!)] first concern is the compliance of the muscle tissue. Compliance, C, is defined as the change in length, $\Delta L$, due to the applied force, $\mathrm{F}$ :

$$
C=\frac{\Delta L}{F}
$$

Compliance is not related to the muscle tissue resistance towards injury. An increase in muscle compliance is associated with a decrease in the energy absorption of the muscle. It is stated [29] that if in vitro the muscle compliance increases, by warming from $25^{\circ} \mathrm{C}$ to $40^{\circ} \mathrm{C}$, the muscle ruptures at a longer length. This however, is not beneficial because the muscle actually ruptures at a lower force [29]. This concern is refuted by Noonan [69] where it is stated that an increase in temperature causes an 


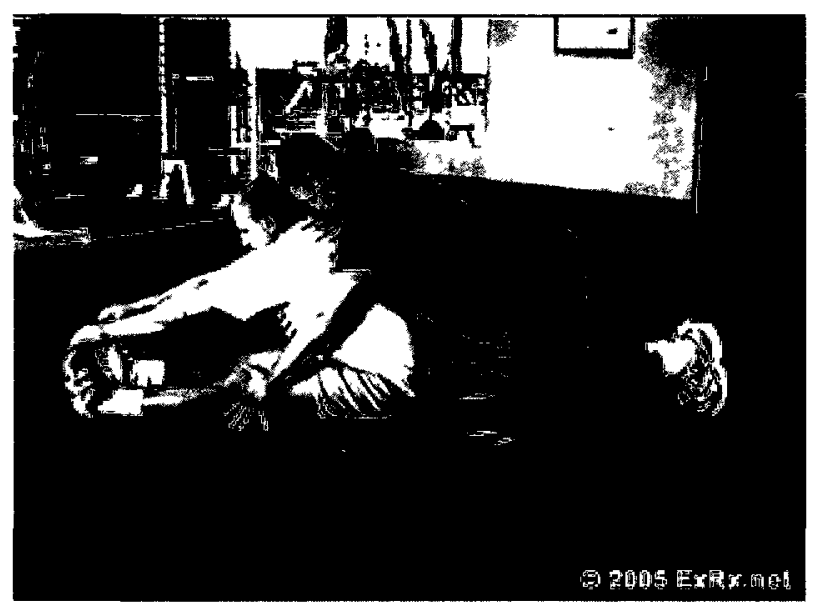

Figure 2.6: PNF Stretching [57]

increase in failure length and failure load. Noonan $\left[6^{(0)}\right]$ mentioned that an increase in temperature, increases the length of muscle to failure and increases the amount of load to failure.

Shrier's second concern relates to the idea that injury happens because the muscle tissues absorb a certain amount of energy or because the muscle tissue exceeds a certain length. Shrier [ $\left.{ }^{\prime \prime}\right]$ refutes the argument in $[21,0,0]$ in which the muscle is thought to be injured after absorbing a certain amount of energy. Ian [29] stated that injury happens because of excessive lengthening of the sarcomeres due to the applied force. Figure 2.8 shows how a sarcomere functions when a muscle is relaxed and during contraction. Injury happens when the sarcomeres are stretched and actin filaments and myosin filaments are no longer overlapped, therefore the applied force travels through cytoskeleton of the muscle fibres and those muscle fibres are damaged. Shrier's hypothesis [29] is that " $\imath t$ us the sarcomere length that is related to most exercuse related muscle strains rather than muscle length." Under this hypothesis, an increase in total muscle compliance is irrelevant. This hypothesis is not supported by biology since lengthening a muscle is related to lengthening a sarcomere. Lengthening of the sarcomeres results in total muscle lengthening.

Shrier's third concern deals with how stretching relates to the compliance of active muscle and passive muscles. In general, injuries happen when the muscle is active; 


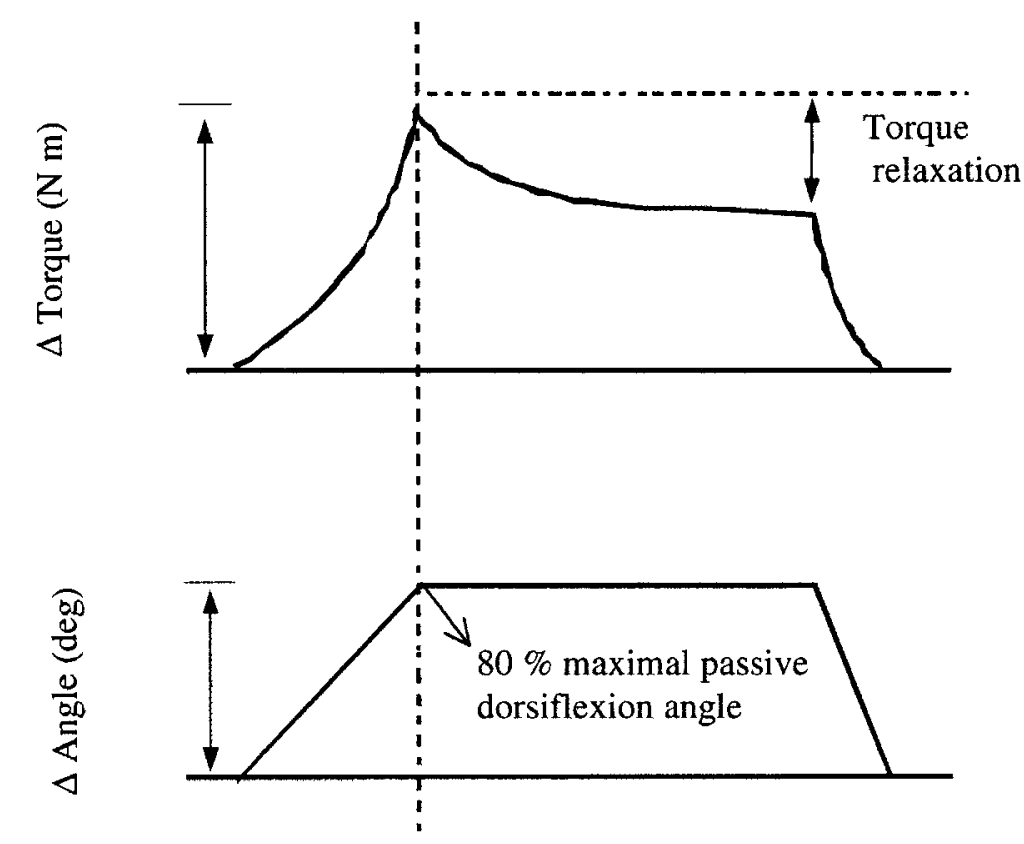

Time (sec)

Figure 2.7: Typical Viscoelastic Behavior of Muscle [6x]

therefore, compliance of an active muscle should be more important than the compliance of a muscle at rest. Compliance of the active muscle is related to the number of actin and myosin cross-bridges. However, compliance of the passive muscle is due to the muscle cytoskeleton. In addition, while active muscle has a lower compliance than passive muscle, it absorbs more energy. These two points do not support the statement in [20] that an increase in compliance is related to reducing the risk of injury.

Shrier's fourth concern is the difficulty in defining the correct stretching techniques. He mentioned that overstretching a muscle definitely leads to injury. However, even strains as small as $20 \%$ beyond the resting fibre length can produce damage. Therefore, defining the correct stretching technique is harder than previously thought.

Shrier's final concern is that an increase in the range of motion is related to an increase in pain threshold rather than a benefit of stretching. It is required in PNF and in static stretching, to stretch until the point of discomfort. He believed this frequently experienced pain supports the position that stretching increases the pain 


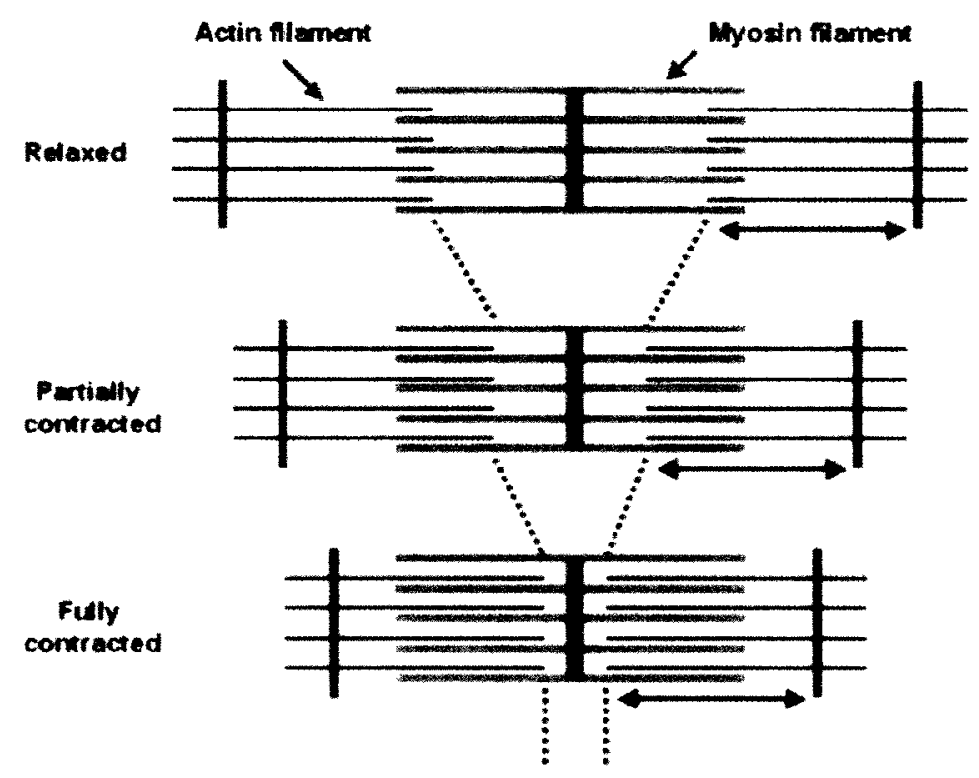

Figure 2.8: Sarcomeres [70]

threshold rather than changing the compliance characteristic of the muscle tissues.

While this chapter refers to athletics, it is useful at this juncture to discuss Shrier's arguments with respect to a pianist. It is necessary to mention not all his arguments are related to piano playing. For instance, the stretching required to prepare pianists for performance is less demanding than most sports-related stretching, as a result the amount of energy absorption in stretching is less of an issue for pianists. In addition, the level of stretching required for playing piano is low enough that lengthening does not exceed the critical length of muscle. Exceeding the critical length may cause injuries. Preparation for playing piano does not involve great energy absorption, excessive lengthening of muscle nor a great range of motion in joints. Nevertheless, co-contraction and compliance of active and passive muscles are issues for the pianist and these are mentioned by Shrier [29].

\subsubsection{Guidelines for Stretching}

As mentioned previously, there is a fine line between stretching a muscle correctly and obtaining the desired result, and overstretching and tiring a muscle by holding it 
in stretched position for too long [10]. In order to reduce the risk of injury; a number of guidelines have been proposed:

- stretching has to be done at least 15 to 20 minutes before exercise and also after exercise $[16,28,48,71]$,

- stretching has to be in harmony with the sport requirements [16,71],

- stretching has to be done carefully and bouncing should be avoided [16],

- stretching has to be held for 15 to 20 seconds to get the desired results [16],

- stretching has to be with a correct intensity to avoid overstretching [16],

- stretching has to be repeated for each muscle groups 3 to 5 times [16].

\subsubsection{Repetition of Movement}

Repetition of movement is the final component of active warm-up, as defined in this thesis and as will be seen it is also part of specific warm-up. In this portion of active warm-up, an athlete focuses on mimicking movements similar to the actual performance [?:]. This stage concentrates on the neuromuscular portions of the body that will be used in the subsequent activity [ $\mathrm{i}]$. For instance, a runner starts to run at a moderate or slow speed shortly before the actual race. One of the advantages of this component is increasing one's focus by concentrating on the techniques. Because an individual focuses on the required techniques for the following event, concentration improves. This, in turn, decreases the chance of making errors. The only difference between this method and the actual performance is the level of intensity [11].

\subsubsection{Specific Warm-Up}

Specific warm-up is the most effective warm-up method in many circumstances due to its effects on the muscles required for the planned activity which include an increase in neuromuscular activity and an improvement in response of the nervous system $[3,7]$. This two-stage of warm-up is composed of mimicking movements similar to the actual performance, and for that reason it belongs to both active and specific warm-up, as well as visualization of the activity [6]. This form of warm-up is extremely important for a sport that requires complex coordination because it allows complex skills to be practiced before an event [7]. 


\subsection{Physiological and Psychological Aspects}

An important benefit of a warm-up routine is placing the athlete in an optimum condition for the following event both physiologically and psychologically [4,11]. Neuberger [13], in a summary of warm-up literature, reported that 14 out of 22 studies showed that warm-up has positive impact on improving performance and reducing the risk of injury, while 7 out of 22 indicated that warm-up improves the performance but not significantly and one study showed a decrease in muscular strength following passive warm-up, but no effect on muscular endurance. These results will be incorporated in Chapter 5, in the synthesis analysis.

The attitude of athletes toward warm-up appears to be one of the factors that may affect the outcome of warm-up. Athletes who believe in the positive effects of warm-up profit more from a warm-up routine than those who associate warm-up with a negative impact $[13,-2]$.

\subsubsection{Physiological Effects of the Warm-Up Routine}

An active warm-up improves the performance and reduces the risk of injury by enhancing the body physiologically $[1,-]$. Most of physiological mechanisms that happen during the active warm-up routine are temperature dependent [-] . As mentioned previously, during aerobic exercise muscles require more oxygen compared to the muscles at rest. As a result, the lungs take in more air and the heart rate increases. This cause dilatation of the blood vessels, an increase of blood volume in the working muscle increases and an elevation of muscle temperature $[3,4,7,11,73,74]$. The muscle cell metabolism increases due to an increase in muscle temperature [4]. In addition, the sensitivity of nerve receptors and transmission speed nervous impulses are affected by temperature. Thus, a slightly higher temperature, on the order of $1.13^{\circ} \mathrm{C}[43]$ is believed to improve the function of the nervous system [11].

One study [4] indicated that the benefits of an increase of muscle temperature are: the rate of abnormal electrocardiorythms decrease due to an increase in the blood supply to the heart; the risk of sport-related injury decreases due to both elevation in the muscle temperature and a decrease in the viscosity of the muscle fibres; and an improvement in performance is associated with the increase in muscle temperature 
which allows a more forceful and rapid contraction of the muscles [i].

\subsubsection{Psychological Effects of the Warm-Up Routine}

The benefits of warm-up come not only from the physiological aspects of warm-up, but also from the psychological effects of the warm-up [22,23]. Psychological warmup makes athletes ready for the performance by improving their concentration [6]. For example, repetition of movements similar to the actual performance, enhances the nervous system and improves the athlete's focus $[6,7]$. It can be concluded that specific warm-up contributes to improve the performance by increasing the concentration and through repetition and visualization reducing the chance of making errors. To demonstrate the importance of the psychological warm-up, Massey [22] showed that subjects who apply physiological warm-up and then are hypnotized to "forget" that they have warmed-up, showed no improvement in physical performance. Also, Malareki [23] reported athletes who "imagined" performing warm-up, showed improvement in their physical performance.

\subsection{Warm-Up and Injury Prevention}

Shellock [:] stated that an increase in muscle temperature is responsible for reducing the risk of injury. Moreover, it is stated that the range of motion of the joint is temperature dependent. At a higher temperature, the joint range of motion is improved due to an increase in the extensibility of tendons, ligaments and other connective tissues $[11,67]$. There are a number of factors associated with a change in results of the warm-up, including the intensity and the duration of warm-up. These are discussed in the section which follows.

\subsubsection{Intensity and Duration of the Warm-Up Routine}

The intensity and duration of warm-up are two factors that can cause warm-up to be beneficial, neutral or harmful $[3,9,11]$. As mentioned in [20], too little warm-up is not beneficial because muscles do not achieve the optimal temperature and too much warm-up is harmful due to fatigue and overuse injury [20]. Neuberger [13] believes that a vigorous and energetic warm-up results in a better performance than a moderate and short warm-up [13]. 
The intensity and duration of warm-up should be correlated to the athlete's conditioning [3]. For instance, an athlete in poor physical condition and an athlete in good physical condition do not require the same intensity and duration of warm-up to reach the same muscle temperature. Hedrick [4] mentioned that the exact intensity and duration of the warm-up depend on the surrounding temperature and the amount of clothing worn. If the room temperature increases or more clothing is worn, the intensity and duration of warm-up can be reduced. It has been argued in [ 1 ] that the beneficial effects of a warm-up routine last for 45 minutes, so it is better to perform the warm-up routine in that time frame, otherwise the need for re-warming the muscles is required. It should be noted that the literature does not provide much more guidance on to the appropriate intensity and duration for warm-up. Finally, warm-up routines are extremely sport- and athlete-specific [4].

\subsubsection{Common Muscular Injuries}

Many factors contribute to muscle injury, for instance: inadequate or no warm-up at all, incorrect warm-up including stretching, excessive or incorrect warm-up, poor conditioning, undernourished muscle and weakness due to a previous injury $[6,-7,0]$.

Two common causes of muscle injury are strain and fatigue. Muscle strain is one of the most common injuries among athletes and it is defined as a partial or complete tear in the muscle-tendon unit [20]. Muscle strains and tearing happen when the tension on a contracted muscle exceeds the muscle's strength $[6,76]$. Tension in a muscle-tendon unit is related to intrinsic (active) and the extrinsic (passive) components [6]. The intrinsic component is related to the active force production of the muscle itself. The amount of active force produced by the muscle corresponds to interaction of the contractile proteins and is proportional to the overlap between thin and thick filaments [6]. Figure 2.9 shows how a muscle contracts and how thin and thick filaments overlap during a muscle contraction. This component is related to the connective tissue within the muscle-tendon unit and is present in unstimulated muscle or muscle stretched beyond the length in which overlap between thick and thin filaments occurs. Tension of the active component, in activated muscle, happens in the normal physiological length of the muscle. Beyond that, most of the tension is due to connective tissues $[6,77]$. 


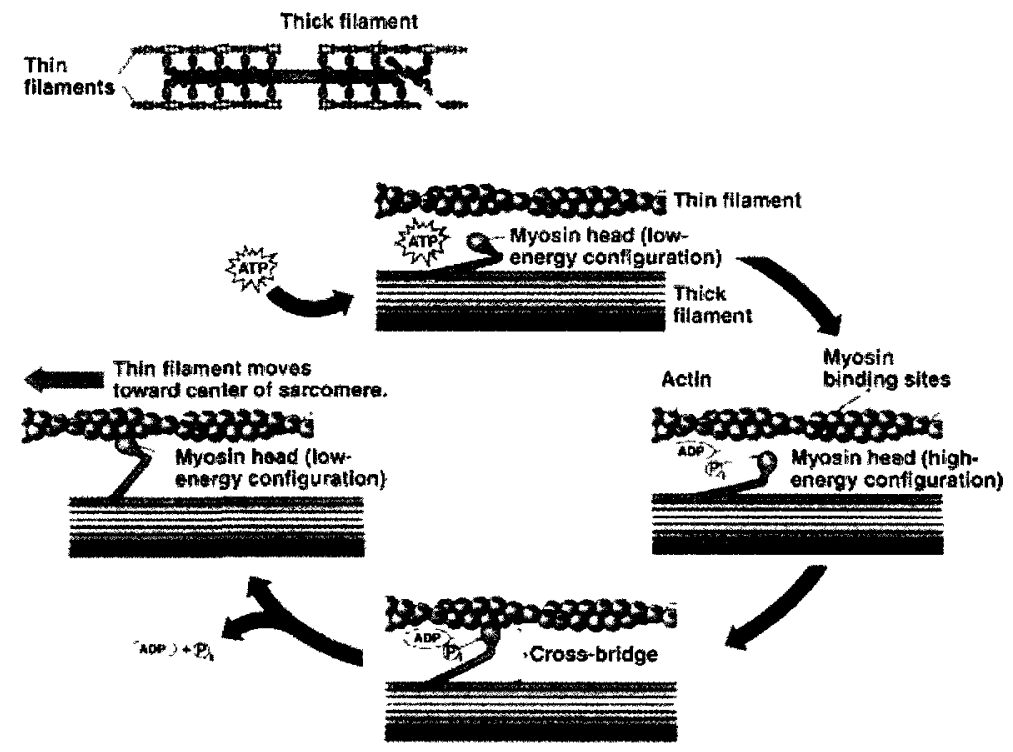

Figure 2.9: Cycle of Muscle Contraction [78]

Fatigue [3:] " is the decreased capacity or complete inability of an organism, an organ, or a part to function normally because of excessive stimulation or prolonged exertion." Fatigue, one of the factors that causes injuries, is the temporary reduction in muscle strength or muscle endurance [6]. Although athletes all around the world perform warm-up prior to performance, it is vital to warm-up in a manner that avoids muscle fatigue. If a poorly conditioned athlete performs an excessive warm-up, it may result in early fatigue [6]. Muscles that are capable of producing a great force and a faster contraction speed and those that are subjected to a great stretch are thought to be more susceptible to injury [6]. Therefore, it is important to warm-up those muscles to reduce the risk of injury [3].

\subsubsection{Cool-Down and Injury Prevention}

Cardiovascular accidents are more likely to occur after a workout [40, 79$]$. This can be prevented by a moderate work-out followed by a cool-down period $[40,79]$. A cool-down is essential in order to [80]:

- remove the lactic acid from working muscles,

- allow the heart rate, breathing rate, and body temperature return to resting levels, 
- prevent too rapid a drop in blood pressure.

While cool-down is not studied in this research, it does have a role to play in injury prevention, especially in athletics. 


\section{Chapter 3}

\section{Physiological and Psychological Effects of Warm-Up on Musicians}

\subsection{Introduction}

The role of human anatomy in practice and performance is an interesting topic that attracts biomechanical engineers as well as those studying music. However, pedagogical recommendations based on anatomy are usually passed on informally and often include incomplete or incorrect knowledge about human anatomy [ $\mathrm{N} 1]$. It was not until the late nineteenth century and early twentieth century that pedagogues began to look at piano playing from the biomechanical perspective $[\times 1]$. Peer advice may be helpful in some cases, but often it conflicts with appropriate piano techniques [81]. Unlike athletes' injuries, pianists' injuries usually happen because of overuse or misuse $[82,83]$. Two main factors are essential if musicians are to perform at their best: first, they must know the instrument and be comfortable with it, and second, they should understand the human body, its limitations and its capabilities [84]. The goal of this thesis is to study the definition of warm-up in music and examine it asa factors that could reduce the risk of injury among musicians.

Bruser [85] and Frederickson [82] mentioned that pianists are cautious about their physical, mental, and emotional health when it is close to a significant performance, but this does not happen everyday. In the early stages of learning an instrument, students typically are taught to focus on the correct posture and preparation techniques. However, all this knowledge may be ignored under the demands and urgencency of preparation for a concert. Under these conditions, pianists may not take the time 
required to prepare themselves for the practice session.

\subsection{Definitions of Warm-Up in Music}

Evidence shows that $30 \%$ to $60 \%$ of pianists suffer from playing related, overuse injuries during their career $[24,81,82,86,87]$. This can happen because of improper warm-up or no warm-up at all. Unlike the definition of warm-up for athletes, warmup for musicians has not been defined clearly. Books and journal articles have rarely given a clear definition of a warm-up routine for musicians [24,81,82]. Frederickson [82] defined warm-up as "the perıod proor to performance that has three stages: a period of light aerobic movements of the required-muscles; a short period of stretching, which is considered as a way of preventing injury and improving flexibility; and third, a period of time for neuromuscular warm-up." Zaza stated in 1994 [24] that warm-up is "a period prior to performance that musicıans began their practice routine by playing slowly on the instrument or a part of the instrument." Thus, Zaza's definition of warm-up in 1994 [21] concentrates on neuromuscular warm-up rather than physiological warm-up. This means her definition emphasizes the importance of performing specific warm-up rather than active or passive warm-up. Zaza stated [21] that there are no harmful effects of performing physical warm-up; however, more research was required to prove whether or not it is a necessary component of the warm-up routine. Comeau [88] concluded from literature review that warm-up is "preparing the muscle and mind for musical actıvity." In the case of musicians, warm-up is defined as [88] "period which provides practice of the required-techniques along with playing slowly and exercising fingers." Norris [89] defined warm-up as "a period prior to performance in which to practice musical techniques." But seen in athletics, Norris does not include aerobic exercises as a part of warm-up routine for musicians. Paull and Harrison [90] defined warm-up as "a procedure to move the muscles gently for a few minutes so as to increase blood circulation." Moreover, they indicated that pianists should be careful to prevent stress and fatigue in muscles [90]. However, some musicians; e.g. winds and string players, perform warm-up before performance, simply to warm-up their instrument and make it ready for the performance. 


\subsection{Types of Music Warm-Up}

In the discipline of music, a warm-up routine can be categorized in two stages: first the time that musicians spend away from the instrument and second the time that musicians spend playing the instrument preparing the body and preparing the mind for the subsequent event [91]. Placing the limited available information in music into the framework defined for athletics, allows the development of a framework for definition of warm-up in music, as shown in Figure 3.1. The framework for definition of warm-up for musicians adopted here has three components: passive warm-up, active warm-up and specific warm-up. Two types of warm-up are regularly referred to when making the body ready for the performance, although not necessarily by name, in the discipline of music; specifically passive and active warm-up [82,91,92]. Also to increase mental focus a musician may use some form of specific warm-up $[\times 2,91,92]$. As will be discussed, Related Movement, replaces Repetition of Movement found in the framework for athletes shown in Figure 2.1.

\section{Warm-Upin}

Musicians
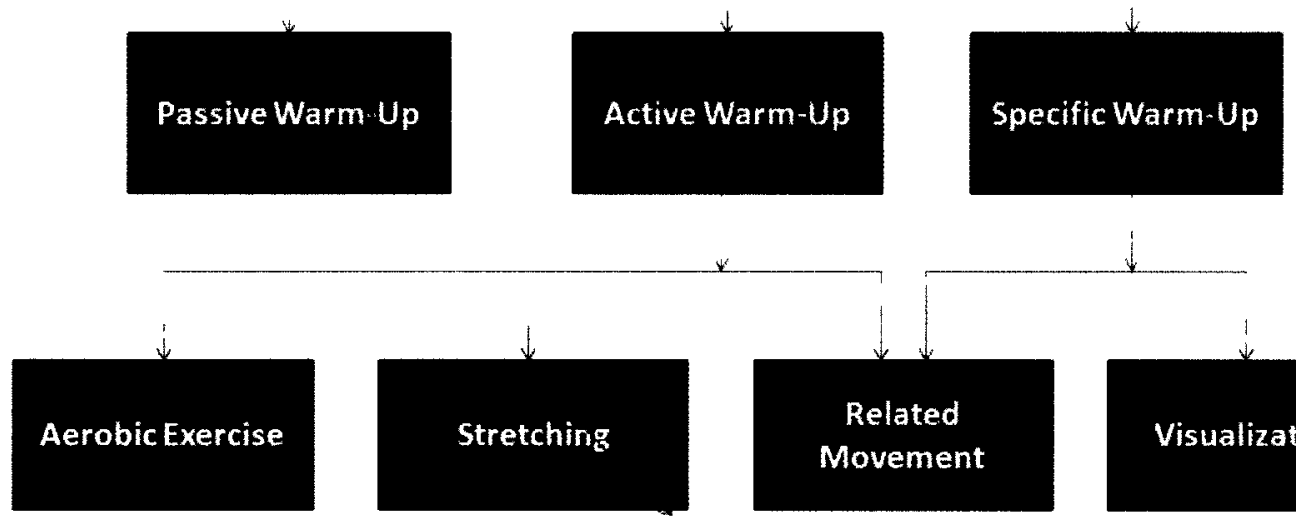

Figure 3.1: A Framework for the Definition of Warm-Up in Music 


\subsubsection{Passive Warm-Up}

As mentioned in Chapter 2, passive warm-up is defined as increasing the temperature of superficial part of the skin or the required-muscles, by some external means. Bruser [93] stated that there are different ways to warm the required muscles: taking a hot shower, washing the hands under warm water or walking for 3 minutes. By definition, the first two methods are considered to be passive warm-up. Also, when massaging hands, with real or imaginary hand lotion is mentioned as another method of warming up passively [91]. The benefits of stretching are more obvious if the muscles are warmed [93].

\subsubsection{Active Warm-Up}

An active warm-up can be interpreted as any light activity that happens before the performance. There are many examples of active warm-up in music books, even though they may not be called "active warm-up". Bruser [9:3 mentioned typical active warm-up routines including lying down on the floor with arms and legs extended up toward the ceiling and moving them in all different directions. The benefit of this method is that muscles get warm without supporting the weight of the body [93]. Another common method to make the body warm is to stand up and shake the limbs [9:3]. Paull and Harrison [9i] described another form of active warm-up in this way: "take a short, brisk walk or jog, or trot up and down the stairs a few times."

\subsubsection{Aerobic Exercise}

There is no general agreement on whether musicians should perform aerobic exercises before playing or not. Zaza in 1994 [21] indicated that aerobic exercises are not a mandatory part of the warm-up for pianists. Paull and Harrison [90] mentioned that exercising aerobically before playing is helpful in injury prevention because warmed muscles are more flexible than cold, unprepared muscles, and that flexibility is a characteristic that reduces the risk of tearing, although tearing a muscle by playing an instrument, is not a typical injury in musicians. Paull and Harrison further indicated that it is easier to play with warm hands; therefore, performing light aerobic exercise prior to the performance is beneficial, to increase the blood circulation through muscles [91]. It is vital for pianists to understand the athletic approach to warm-up in order to be able to determine the best approach to increasing the temperature of the 
body, but particularly of the hands [91]. Paull and Harrison [91] believed that going to the gym and trying to keep the body fit are primary steps in playing well.

\subsubsection{Stretching}

Most pianists agree that stretching before playing is beneficial and most injury prevention programs include stretching as an important part of their agenda [24]. Zaza noted that the effects of stretching on musicians may depend on the musician's attitude towards it [24]. Some believe that stretching reduces the risk of injury, while others do not believe that stretching prevents injury. Paul and Harrison [90] stated two main benefits of stretching:

- to increase muscle flexibility and maintain a muscle's full extensibility,

- to be able to lengthen a muscle without the risk of tearing.

Paull and Harrison [\%] gave the following guidelines for stretching in order to reduce the risk of injury. It is important to mention these guidelines are similar to those seen in athletics:

- stretching should be done slowly and gently,

- stretching should not be accompanied by bouncing,

- stretching should not last until the point of discomfort,

- stretching should contribute to a reduction, over time, of the tightness and the stiffness of muscles,

- stretching should be repeated 3 to 4 times for maximal effectiveness.

\subsubsection{Related Movement}

Based on the framework used in this thesis, the use of related movements is the final stage of the active warm-up routine. Here, musicians perform motions similar to the ones required for the actual performance [91]. In this case, the warm-up material is related to the actual piece of music in terms of techniques to be used [91]. Paull and Harrison [91] indicated that musicians can play anything in the last stage of their warm-up, as long as they remember to keep the body movements gentle, play a variety 
of notes, play with moderate speed and have a neutral body position. While these related movements are an essential component of warm-up for musicians, careless repetition is dangerous and might limit the body to a single position [91].

\subsubsection{Specific Warm-Up}

A specific warm-up in music is interpreted as playing with the instrument [91]. There are different ways of performing this type of warm-up. Musicians can either follow a very restricted technical exercise or they can play what they feel comfortable with [91]. Both are fine provided that the musician remembers the athletic principle that practice should be at a moderate level. Musicians should also play a variety of notes in this stage [91]. A specific warm-up can also be interpreted as a neuromuscular warm-up which increases the level of coordination and skill [24].

\subsection{Physiological and Psychological Aspects}

Playing a piece of music, especially using the piano, requires a high level of coordination between the hands, the fingers and the mind. Therefore, pianists should be physically and mentally ready to be able to perform $[\times 2,94]$. Frederickson [ $\times 2]$ mentioned that both physiological preparation and psychological preparation before the performance are the most important factors in achieving better performance and in preventing injury.

\subsubsection{Physiological Effects of the Warm-Up Routine}

Music students do not view physiological warm-up as an important part of their warm-up routine until they suffer a reduction in their physical health [82]. Frederickson [82] recommended that music students prevent injuries by physical preparation before a performance. Bruser [9:3] also emphasized that playing with warmed muscles reduces the risk of injury when compared to playing with unwarmed muscles.

\subsubsection{Psychological Effects of the Warm-Up Routine}

Visualization before a performance helps music students to perform better [24]. Bandura $[25,26]$ mentioned that when people visualize themselves performing an 
activity, electromyography of the required-muscle groups for that specific activity changes as though they actually performed the activity. Similar to athletics, research shows that in a complex skill, such as playing a piece of music, the quality of playing increases when physical rehearsal and cognition are combined when compared to physical exercise alone $[24,25]$.

There are several psychological methods that help musicians perform better. Zaza [24] stated that musicians can improve their playing by practicing their hearing skills, in a way that they can visualize hearing what they are going to play. Another way is try to imagine practicing the material that they want to play.

Managing both stress and anxiety is an important factor in a musician's career. It is vital for music students to be able to control these factors in their preparation time before performances. One way to control these factors is by visualizing the performance, and in doing so, increase one's confidence $[24, \cdots 2]$.

\subsection{Warm-Up and Injury Prevention}

There is a substantial difference between musicians and athletes in terms of physical preparation [ $\left.{ }^{1}\right]$. Musicians often spend this time alone, while athletes may be professionally supervised [91]. This solitary nature of a musician's preparation time may affect the quality of playing because the right posture and safe habits are less likely to be taught and reinforced without supervision [91]. Correct warm-up procedures could be one of the factors that music students are not able to learn because of this difference in preparation time. Many music students graduate without knowing these critical points [91]. Developing safe and efficient practice habits to reduce the risk of injury is vital [91]. It may be useful to teach music students to think like athletes and to learn to incorporate the principles of sports medicine and psychology [91].

\subsubsection{Intensity and Duration of Practice}

It is impossible to provide a guideline to indicate exactly how much practicing is safe for an individual. Bruser [95] stated that practice time differs between amateur and professional musicians. Amateur musicians may need more time to get comfortable with a piece of music when compared to professional musicians. 
It should be noted that one of the risk factors contributing to injury is bad posture $[24,82]$. Music teachers should teach their students the right posture and how to maintain it through the entire session [82]. Teaching the right posture is vital in playing piano and usually the first section of a piano course is allocated to this, "The human body is capable of fulfilling all pianistic demands without any harm and pain. Insecurity and lack of technical control are symptoms of uncoordination rather than a lack of practice, intelligence or talent" [96].

Breaks during practice may avoid fatigue, overuse and stiffness [82, 97]. Bruser believes it is crucial to take breaks during practice time to relieve the load on the required muscles [97]. In addition, he suggests that the brain needs to rest for 10 to 15 minutes after each 45-minute practice session [97]. During the break, musicians can perform light activities, such as walking, lounging on a comfortable couch or drinking tea [97]. Heavy activity is to be avoided. A "break" does not mean leaving the practice area since even changing the position related to the instrument can be considered as "break" for the body [91].

The quality of the practice session is key to playing well. To have higher quality in playing, practice should be performed during the time of day that the musician feels fresh and stress-free [y-]. A sudden increase in the duration of playing is one of the main causes of injury. Thus, musicians must learn how to increase their practice sessions, especially before auditions, competitions and performances, without the risk of injury [24].

In playing the piano, arms and shoulders perform a variety of motions. Some of these motions will be repeated in a playing session. This repetition might be the reason that arms and shoulders are usually sources of pain [84]. Nevertheless, injury is not always a result of inappropriate techniques [81]. Genetic factors also play a major role in injury development. Some individuals seem to become injured more easily than others $[81]$.

A variety of injuries among pianists may be attributed to incorrect practicing and/or performance [81]. As will be seen, muscular pain syndrome, carpal tunnel syndrome, focal dystonia, tendinitis, and tendon entrapment are some examples of injuries often attributed to incorrect practicing. 
Pianists should change the way they look at injury and try to be aware of the early signs of injury. Amateur students should learn from the beginning not to neglect any pain or uncomfortable condition [98]. Obviously, it is easier to treat a potential injury in primary stages rather than once it is in an advanced and developed stage [82].

Wristen [81] stated that the most important factor in injury prevention is to avoid a sudden increase in the intensity of practice. In addition, warming up the muscles allows them to reach their optimal functional temperature, and function better. Nevertheless, cooling down after practice is recommended to prevent injury [81].

\subsubsection{Common Muscular Injuries}

Clearly, for pianists, injuries to the hands are particularly concerning. According to Mason [99], "The hand is a highly complex structure with 27 bones, 18 joints, and 39 intrinsic and extrinsic muscles with over 20 degrees of freedom. Movement of the fingers requires a coordinated interplay of both extrinsic and intrinsic muscles." ${ }^{1}$ The complexity of this delicate structure is the cause of many injuries. Mark [100] mentioned the following factors as contributing to injuries among pianists:

- awkward position

- excessive force

- co-contraction

- static muscular tension

\subsubsection{Carpal Tunnel Syndrome}

The carpal tunnel is the bony canal on the palm side of the wrist through which messages of the median nerve passes [37]. Carpal tunnel injury is a type of nerve entrapment that occurs in the wrist [37]. The carpal tunnel is surrounded by a band of fibrous tissue, which is responsible for supporting the joints. As shown in Figure 3.2, carpal tunnel injury causes irritation and compression of the median nerve in the wrist. In this injury, the nerve is compressed within the carpal tunnel. The signs 


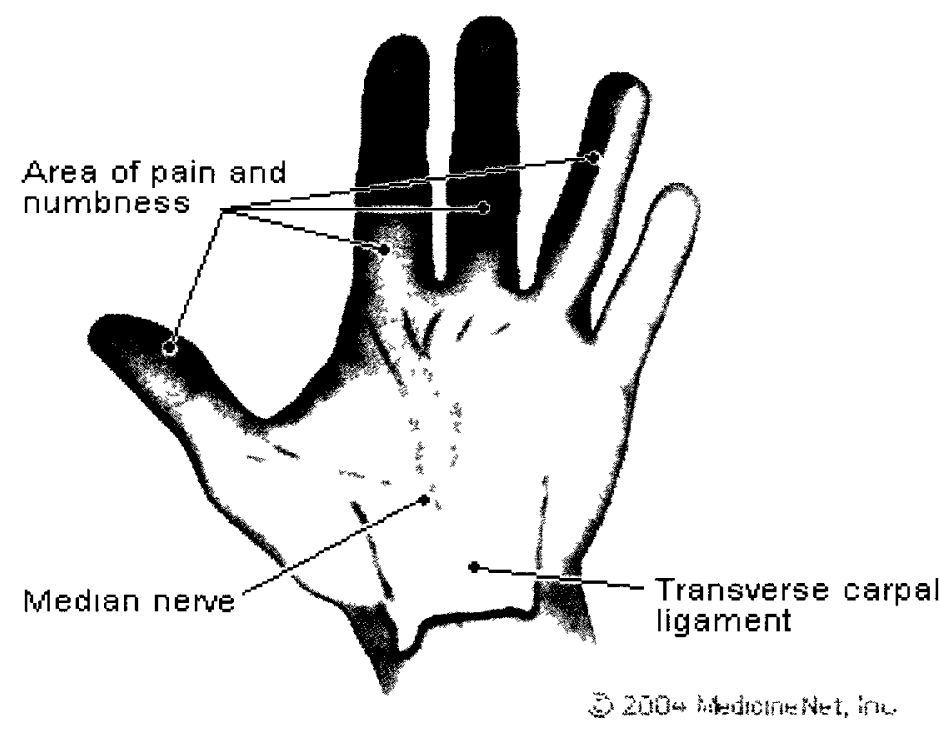

\section{Carpal Tunnel Syndrome}

Figure 3.2: Carpal Tunnel [101]

of carpal tunnel syndrome include numbness of the hand, tingling, wrist pain, and weakness in the grip $[: 7]$.

\subsubsection{Overuse Syndrome}

Overuse syndrome is the most common injury among musicians and has been reported for over 100 years [102]. While there are different definitions of "overuse", they all refer to continuous and excessive use of certain muscle groups in performing a certain activity [102]. Overuse is associated with the occurrence of muscle spasms and pain in those muscle groups [102]. Overuse syndrome occurs as a result of specific hand motions made during playing [87].

Common symptoms of overuse syndrome include pain, weakness, swelling, loss of response and loss of control [102]. A recent study indicated that immobilization, which is the traditional treatment, is not the best treatment for overuse syndrome [84].

\footnotetext{
${ }^{1}$ Intrinsic muscles are in the hand while extrinsic muscles are in the forearm.
} 
Physiotherapists no longer advocate total rest from playing. Instead, musicians are encouraged to play with the instrument in a manageable but restricted timeframe [84].

\subsubsection{Focal Dystonia}

Focal dystonia is defined as a disorder in which there are irregular movements in a muscle or a group of muscles. Figure 3.3 shows a typical focal dystonia in the right hand of patient. It usually affects the parts of the body that are subject to constant use in an activity. In this situation, the affected part does not respond to the required task, but acts normally in other activities [100]. Twitches and repetitive posture tics are observed in the affected parts. Focal dystonia is recognized as a loss of motor control of one or two fingers [10:3]. In this injury, the brain's ability to control those fingers is reduced.

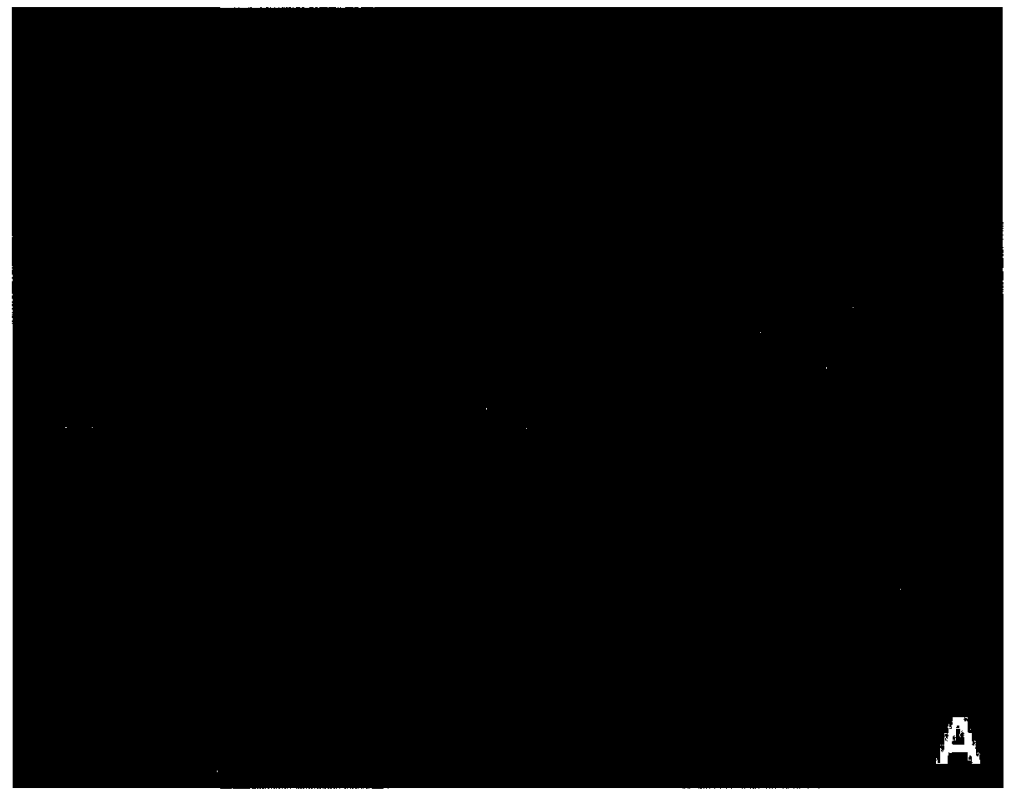

Figure 3.3: Focal Dystonia in the Right Hand [104]

\subsubsection{Tendinitis}

Tendons are fibrous tissues that connect muscle to bone, as shown in Figure 3.4. Tendinitis is a painful inflammation, and irritation of a tendon. Tendinitis is a common result of overuse and is usually accompanied by significant pain. Joint movement 
is associated with the smooth motion of tendons. Common causes of tendinitis include repeated motion of the tendon over a long period of time, overuse and sudden movements $[100,105]$.

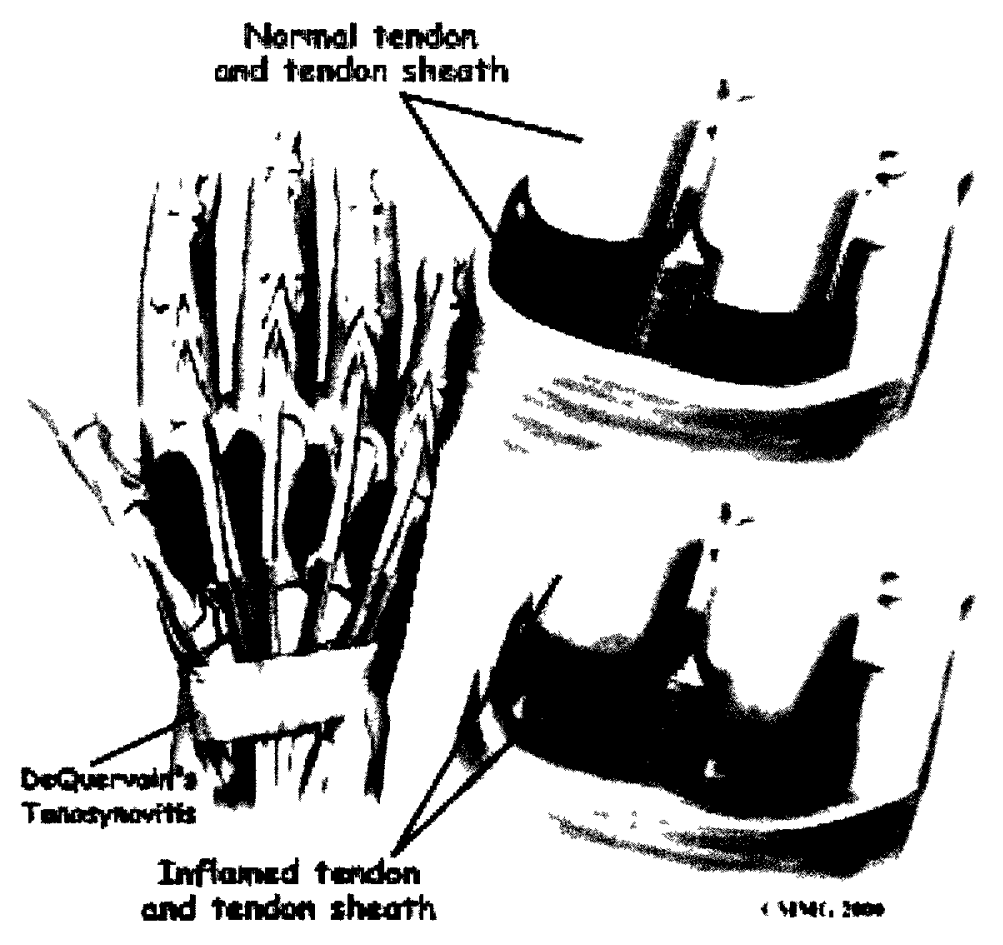

Figure 3.4: Tendinitis [106]

\subsubsection{Cool-Down and Injury Prevention}

While the focus of this thesis is warm-up, having a period of time for cool-down is an important part of injury prevention [81]. For example, Zaza [24] mentioned that having a stretching period after playing can be considered to be one of the primary requirements for reducing the risk of injury. Musicians should include a cool-down time with the instrument after finishing the practice time to cool down. The material that musicians can play during a cool-down time period can be the same as material of warm-up time [107]. 


\section{Chapter 4}

\section{Warm-Up from the Perspective of Music Students}

\subsection{Informal Survey of the Attitude of Music Stu- dents}

The author was informed that string players from an Ontario high school were assigned the task of describing the warm-up procedures they follow prior to playing. Permission to attend the students' presentations on the subject was obtained from their teacher. The students' descriptions of their warm-up routines were noted; however, the individual responses of the 10 students remain anonymous. The average age of the students was 15 .

Most students referred to "general stretching" as a part of their physiological preparation. "General stretching" from their perspective is stretching the forearms and arms, the back and the neck. Figures 4.1 to 4.4 show the author's interpretation of the students' descriptions of stretching.

Some of the students reported that they had already encountered different levels of neck, back, shoulder and wrist pain. In addition, some students mentioned that they had also experienced tendinitis. The warm-up routines as described by the students are presented below. 


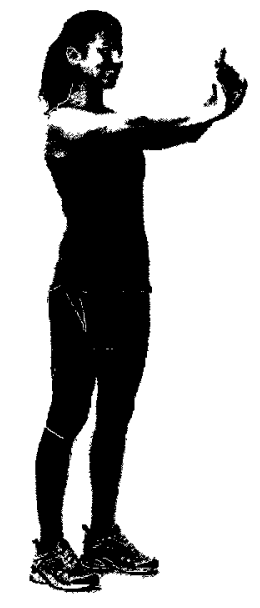

Figure 4.1: Forearm Stretching [108]

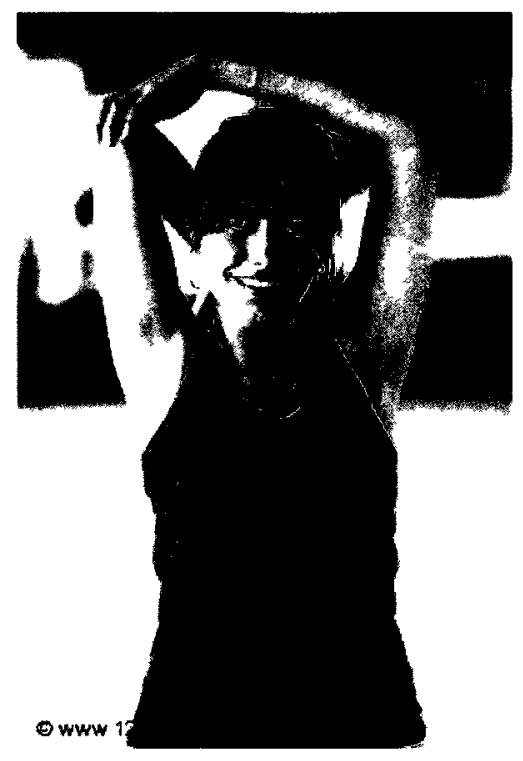

Figure 4.2: Arm Stretching [109] 


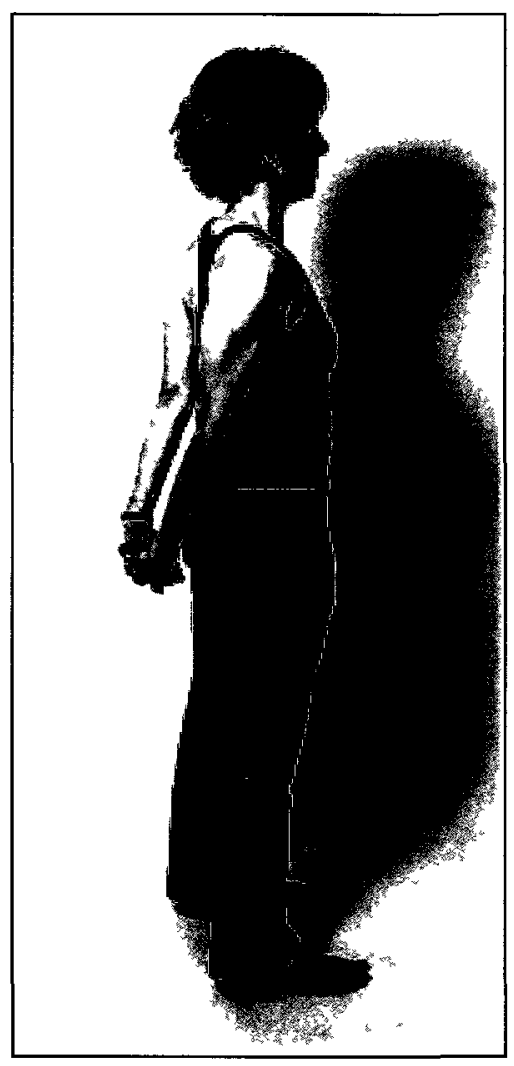

Figure 4.3: Back Stretching [1:10]

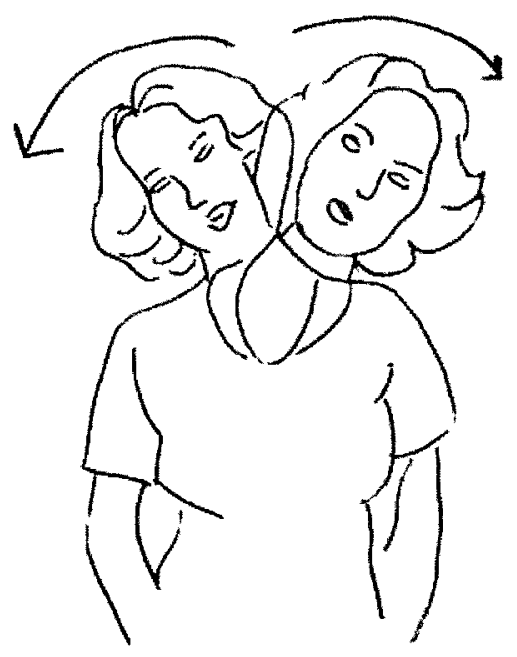

Figure 4.4: Neck Stretching [111] 
- Student A: This student has tendinitis and a neck problem. As a result, her physiotherapist assigned a predefined warm-up with a duration of 20 minutes. For the physiological part of the warm-up, she crosses her hands. The hand on top pulls the hand below until she feels stretching in her forearm as shown in Figure 4.5. She switches hands and repeats this procedure before playing, during playing and after playing. For the psychological part of the warm-up, she is not restricted to any particular warm-up routine. She plays different pieces that she feels are similar, in terms of musical dynamics, to what she is going to play later. In playing these pieces her body performs the movements that are similar to the actual piece movements.

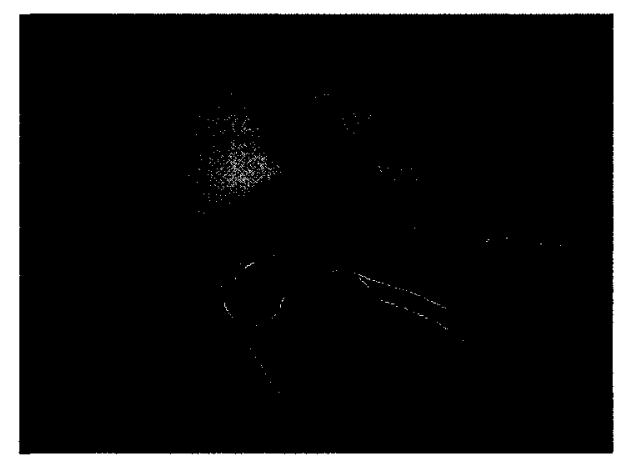

Figure 4.5: Stretching Described by Student A and Student F

- Student B: This student believes stretching prevents injury. Her physiotherapist recommended a prescribed warm-up routine which meets her needs. For the physiological part of the warm-up routine, she places an elastic band around two of her fingers and moves them apart from each other as shown in Figure 4.6. She then puts the elastic band around another pair of fingers and repeats the stretching until all the fingers have been stretched. This, she believes, increases the "flexibility" of fingers. As part of her physiological warm-up routine, she stretches her hands by keeping them horizontal to her body with her palms facing out for 5 seconds as shown in Figure 4.7. She repeats this procedure 10 times. For the psychological part of the warm-up, she practices a piece in which she concentrates on moving her fingers in harmony with one another. She visualizes her playing before the performance. 


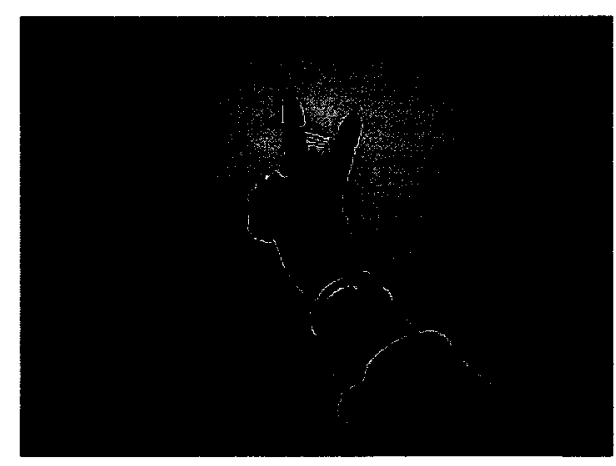

Figure 4.6: Finger Stretching Described by Student B

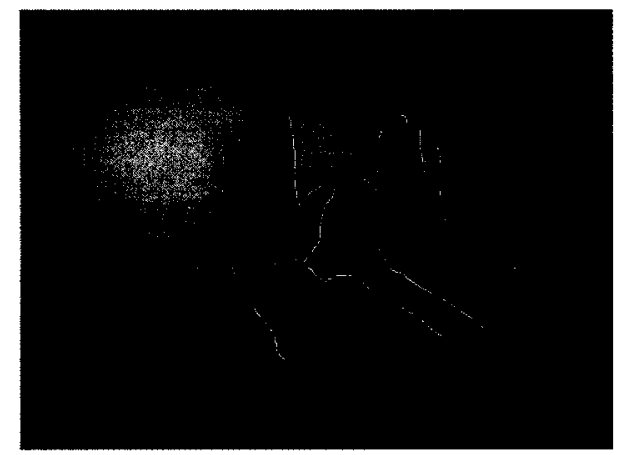

Figure 4.7: Hand Stretching Described by Student B

- Student C: This student suffers from back and shoulder pain. As a result, in her warm-up routine she concentrates on stretching her back. Her warm-up routine was recommended by her strings teacher. For the physiological part of the warm-up routine, she stretches her hands by keeping them horizontal and locking the fingers together, and then pulling her hands out as hard as she can, as shown in Figure 4.8. In addition, she works on increasing coordination between her fingers by lifting fingers 1 and 3 together and then fingers 2 and 4 together as shown in Figure 4.9. For the psychological part of the warm-up routine, she plays a familiar and well-known piece of music and concentrates on the quality of her playing.

- Student D: This warm-up routine does not include stretching as part of the 


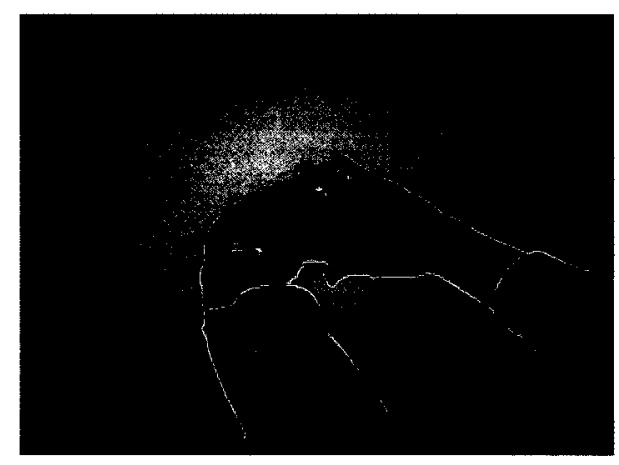

Figure 4.8: Hand Stretching Described by Student C

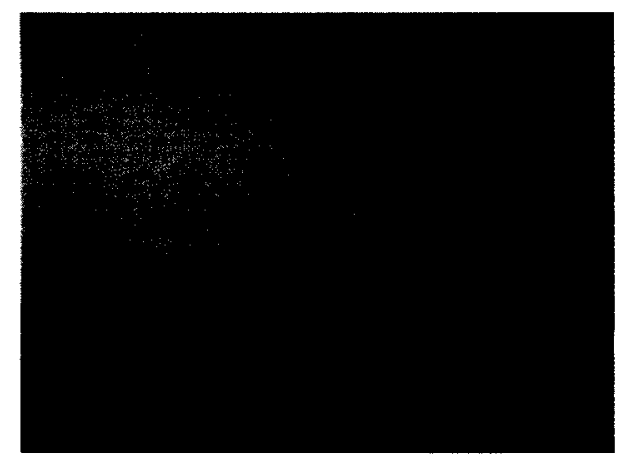

Figure 4.9: Finger Stretching Described by Student C

physiological warm-up. In her warm-up routine, the student concentrates on the psychological part of the warm-up more than the physiological part. For the psychological part of the warm-up, she plays a piece of music that she knows very well. Depending on the actual piece that she wants to play, she "adds some notes" to the piece that she has chosen for the exercise; this way her exercise piece is similar to her actual piece. The exercise piece includes all the gross and fine motor skills that she needs for the actual playing.

- Student E: This student follows general stretching approach as described earlier to stretch the required parts of her body. Since she believes she has cold hands, she shakes her hands quickly before playing. She believes this increases the blood flow through her hands and as a result, increases the flexibility in her hands. She sometimes wears more clothes on to increase her body temperature. She believes the key to playing long and comfortably is to stretch the hands. For the psychological part of the warm-up routine, she plays a piece of music 
that she knows very well. She starts with soft notes in terms of applying force over the strings and moves gradually to stronger notes. She is careful to have dynamic control over her warm-up practice.

- Student F: This student emphasizes stretching of her hands as a major part of her physiological warm-up routine. She crosses her hands as shown in Figure 4.5 and uses the hand on top to pull the hand below until she feels stretching in her forearm. She holds her hands in the stretched position for 10 seconds and repeats this procedure 5 times. She then switches hands and repeats the same procedure. For the psychological part of the warm-up routine, she is not restricted to any specific routine. She plays pieces that she knows well until she feels confident. This student visualizes her playing before the event.

- Student G: This student has tendinitis and a shoulder problem. Therefore, she emphasizes stretching as a major part of her physiological warm-up routine. She stretches her shoulders by keeping her back straight and locking her hands behind her back and moving them down and up as shown in Figure 4.10. For the psychological part of the warm-up, she picks a piece of music that includes all the skills that are in the actual piece. In addition, she plays a piece of music fast which she believes helps her to have good control over her bow hand.

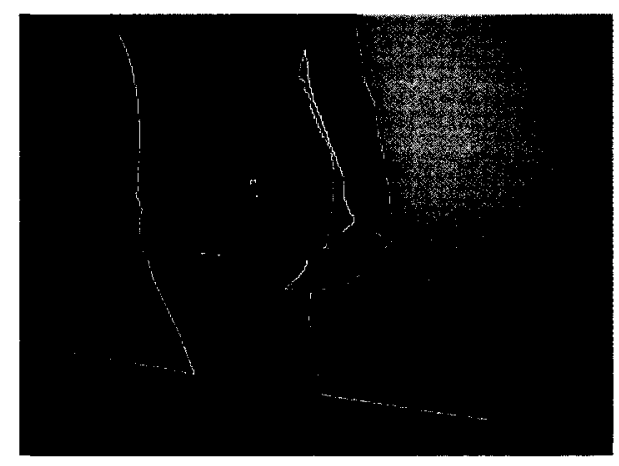

Figure 4.10: Stretching Described by Student G

- Student H: This student stretches for 10 to 30 minutes before playing. She emphasizes stretching any part of body that feels sore that day. For the physiological warm-up, she plays different pieces. She never sticks to one particular piece. The important point about the chosen piece is that it should contain all 
the gross and fine motor skills. The final part of her warm-up routine is playing a piece quickly which the student believes will increase the blood flow through the fingers.

- Student I: This student stretches 10 minutes before playing. Her warm-up routine is to keep her hands horizontal toward her body with palms facing out and holding this position as shown in Figure 4.11 for 10 seconds and repeating this 5 to 7 times. She stretches her back by locking hands together and trying to keep her back straight and staying in this position for 10 seconds, as shown in Figure 4.12. In addition, she washes her hands under warm water before playing to warm up her normally cold hands. For the psychological part of her warm-up routine, she usually picks a piece of music that is difficult for her to play to feel confident about playing the actual piece. This student visualizes her playing before the performance.

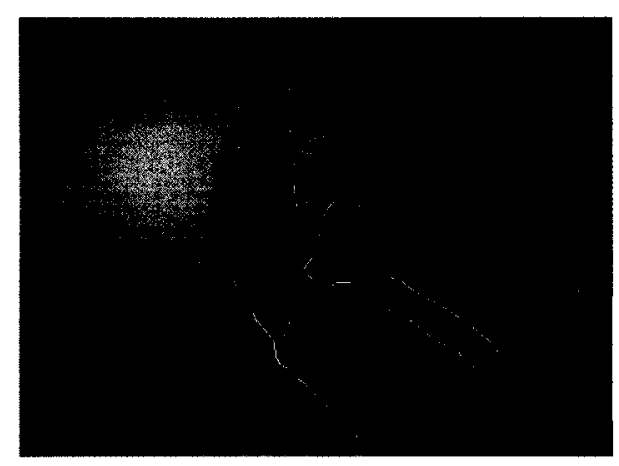

Figure 4.11: Hand Stretching Described by Student I

- Student J: This student concentrates on stretching as a main part of her physiological warm-up and she follows a general stretching approach. To meet the psychological part of the warm-up routine, she does not insist on any specific skill. She emphasizes playing a piece that causes the bow hand to move more frequently. At the end, she plays a piece that she knows very well to increase her confidence. This student visualizes successful playing before the event. She believes this helps the student to gain confidence. 


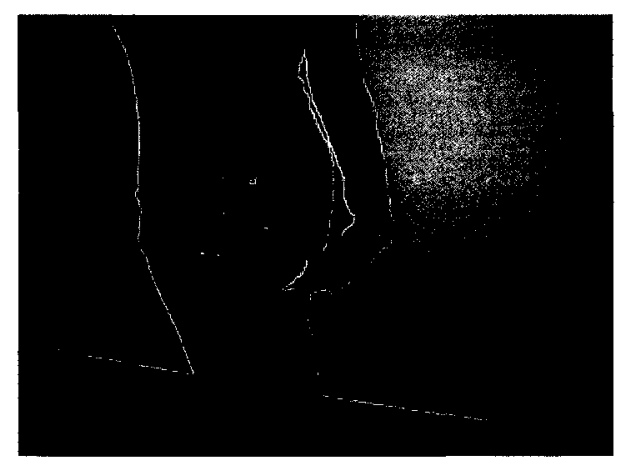

Figure 4.12: Back Stretching Described by Student I

\subsection{Survey Results}

When considering the validity of the data presented and the extension to the general musical population, it should be noted that these data were gathered from a small class, with a specific graded assignment and an observer present. Students may have answered or presented what they believed the teacher and the observer expected to hear.

Even so, it is clear there are useful outcomes. Most of the students, whether realizing it or not, include both physiological and psychological warm-up as part of their warm-up routine. On the physiological side, two of the ten students mentioned warming up their hands through passive warm-up, even though they did not recognize passive warm-up as a type of warm-up. None of the adolescent string students include aerobic exercise as a part of their active warm-up or preparation. Nine of the ten mentioned performing stretching before playing, so stretching plays an important role in their preparation. They mentioned stretching as a way to prevent injury from happening and prevent injury from re-occurring. One of the students, student $\mathrm{H}$, mentioned she plays a piece very fast to increase the blood flow in her fingers. While this is not a correct understanding of biology, since there are no muscles in fingers, the student believes it has a positive impact on her playing. On the psychological side, all the students mentioned playing a piece of music with which they are comfortable, as a way to increase their confidence level. This demonstrates the use of psychological warm-up in the discipline of music. 
Obviously, this group is not a group of normal teenagers who play music just for fun. Each member of this group is serious and plans to continue playing. Of all the outcomes mentioned above, the lack of aerobic exercise stands out. Performing aerobic exercise before stretching seems to improve the quality of the performance and reduce the chance of injury. Using the framework for the definition of warm-up that has now been developed in the discipline of music, it seems appropriate to suggest that students could benefit from the inclusion of aerobic exercise in their warm-up. In the next chapter, the effectiveness of aerobic exercise in music warm-up will be studied and the recommendation of whether or not to include aerobic exercise will be considered. 


\section{Chapter 5}

\section{Synthesis Analysis of the Warm-Up Routine in Both Disciplines}

\subsection{Introduction}

There are many factors involved in the development of playing-related injuries among musicians, especially pianists. These include: years of experience; age; gender; playing techniques; playing posture; breaks between practice sessions; and warm-up prior to performance $[112-111]$. The aim of this study is to analyze the effects of warm-up as one of the important factors in injury prevention in musicians.

It appears there are many tasks that demand physical preparation, or warm-up, in order to reduce the risk of injury. As has been seen, it is suggested than even gardeners perform some form of warm-up before starting their activities [2]. Warmup and its effects are well understood in the discipline of athletics where, over several decades, researchers have investigated different types of warm-up and their effects on the human body. In athletics, it is understood [6-8] that warm-up is essential for injury prevention and performance enhancement. On the other hand, in music, there is little available literature investigating the physiological and the psychological effects of warm-up as factors that could prevent injury in musicians. For this reason, in this chapter, a framework for definition of warm-up and effects of different types of warm-up in both discipline is presented, this framework is developed based on comparison of the established framework in music with the framework for definition of warm-up in athletics. 
Watson [115] believes that to have a risk free performance, it is essential to educate an individual about human anatomy as well as the warm-up routine and its effects on the human body. Athletes are more educated in these areas when compared to musicians [91]. Therefore, studying the warm-up procedures of athletes could help in clarifying a poorly studied area of warm-up in music.

Musicians may not perceive that the use of an athletic-based warm-up has any value, since the nature of the physical effort involved in playing music is very different from that of, for example, playing tennis. Nevertheless, the human body and its physiological and psychological reactions vary only in degree. For example, by increasing the heart rate, the body temperature rises, regardless whether the person is playing a piano or playing tennis.

\subsection{Methods and Materials}

More than 100 papers in both disciplines regarding warm-up definition and its physiological and psychological effects on the human body have been reviewed for this thesis. Papers that did not focus on warm-up as a method that prevents injury were excluded. The question might be posed as to whether the difference in the level of physical effort involved should exclude any of the components of the warm-up as defined in the framework. The following factors have been shown to play a role in the relationship between warm-up and injury prevention:

- passive warm-up

- active warm-up

- specific warm-up

- aerobic exercise

- stretching

- repetition of movements

- visualization 
This chapter is organized in two parts. In the first part, the physiological and the psychological effects of warm-up in both music and athletics are analyzed. The discussions in this part are based on the opinions expressed in the cited literature. Also, a comparison of the opinions presented in the music literature and information gathered from the informal survey of Ontario music students is presented. In the second part, the effects of warm-up on injury prevention in both disciplines based on quantitative data presented in the literature are analyzed.

\subsection{An Analysis of Published Opinions on Warm- $\mathrm{Up}$}

As stated in Chapter 1, the warm-up routine is defined as any physiological and psychological preparation that an individual performs before the event. Figure 5.1 shows the framework developed for the definition of warm-up for both disciplines. As has been shown in Figure 5.1 , there are three well understood types of warm-up in both disciplines: passive warm-up, active warm-up and specific warm-up. Both active and specific warm-up include several stages, whereas passive warm-up does not. Active warm-up consists of aerobic exercise, stretching and repetition/related movements, depending on the discipline. Specific warm-up consists of repetition/related movements and visualization. Repetition/related movements belongs to both active and specific warm-ups. Based on this study, it is also useful to divide warm-up regarding to its effects on an individual: unfocused physiological, focused physiological and focused psychological effects. These outcomes are the result of reviewing papers in both disciplines. As has been shown in Figure 5.1, passive warm-up has unfocused physiological effects; active warm-up has both unfocused and focused physiological effects as well as focused psychological effects; and specific warm-up has focused physiological and psychological effects. These components and effects will be explained in detail in Section 5.3 .

Table 5.1 shows the variations in definition of warm-up routines in both disciplines based on the opinions expressed in the available literature. The framework of Table 5.1 was developed using the author's definition of the warm-up as stated earlier. In some of the literature, warm-up and stretching are defined as two different tasks. 


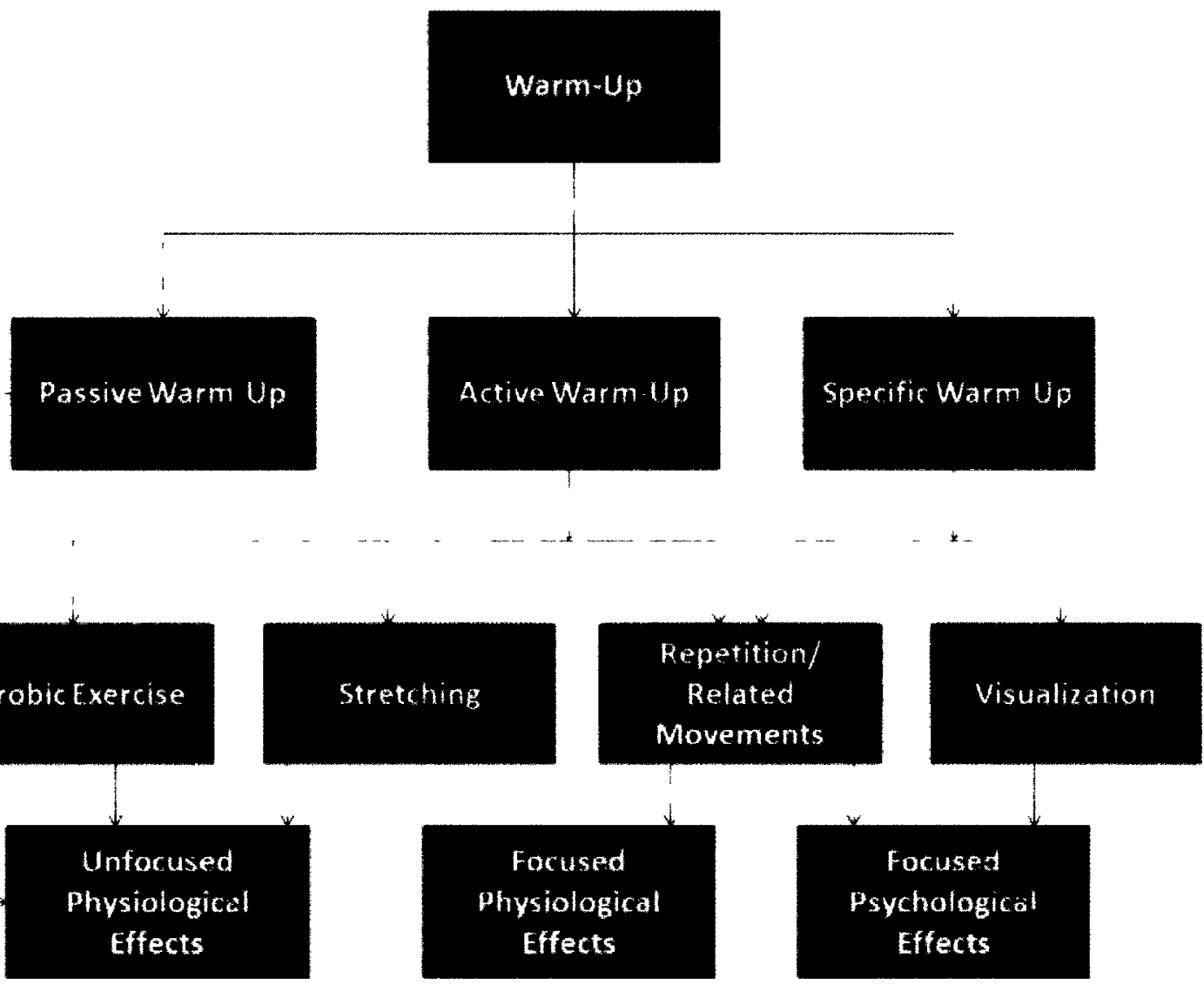

Figure 5.1: A Framework for the Definition of Warm-Up and its Effects 
This does not conflict with defining them as two components of the active warm-up in Table 5.1, since both of them will be applied before the actual performance. As is shown in Table 5.1, there are differences between the way that athletes and musicians warm-up. For example, aerobic exercise is an unavoidable component of active warmup in athletics, but as previously mentioned, it is not a well-understood component of active warm-up in music. Specific warm-up is a necessary part of a musician's preparation, but it does not seems to be the same for athletics. It is worth pointing out that the reminder of the Figures of this chapter are derived from Table 5.1.

Figure 5.2 shows the opinions expressed about different types of the warm-up in the available music literature, athletics literature and by the music students. As is shown in Figure 5.2, the active warm-up is noted as being required by all three groups; i.e., $100 \%$ because there is at least one component of the active warm-up in each group that is believed to be performed regularly ${ }^{1}$. Specific warm-up is similarly noted as being $100 \%$ as it is required by opinions expressed in the music literature and opinions of the music students.

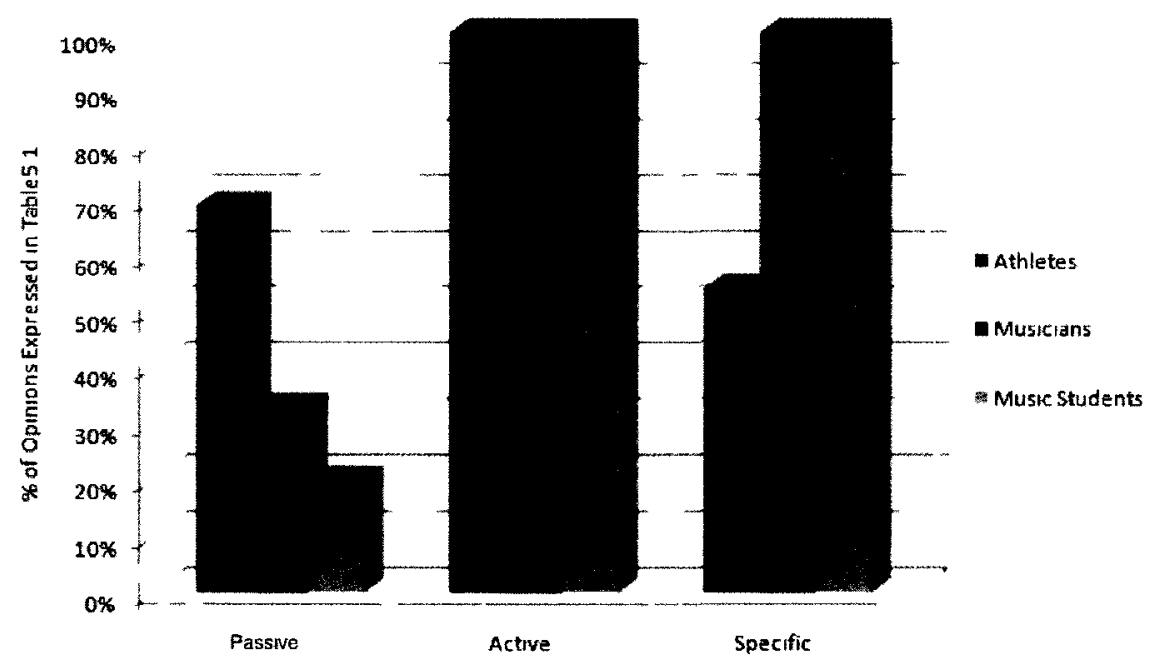

Figure 5.2: Comparison of Different Types of Warm-up Among Athletes and Musicians and Music Students

\footnotetext{
${ }^{1}$ For example, in Table 5.1. 13 of 13 papers clearly include the aerobic component as a part of active warm-up
} 
Table 5.1: Definition Variations of Warm-Up Routine in Both Disciplines. [Research Types are EX: Experimental study, O: Opinion, S:study, SS: Survey of several studies, $\sqrt{ }$ : it is part of warm-up, - : it did not get discussed in this paper, $\sim$ : it is not clear if this is part of warm-up or not, X: it is not part of warm-up.

\begin{tabular}{|c|c|c|c|c|c|c|c|}
\hline \multirow[b]{3}{*}{ Paper } & \multirow[b]{3}{*}{ Activity } & \multirow[b]{3}{*}{ Type } & \multicolumn{5}{|c|}{ Type of Warm-Up } \\
\hline & & & \multicolumn{3}{|c|}{ Physiological } & \multirow{2}{*}{$\begin{array}{l}\text { Combined } \\
\text { Movement } \\
\text { Repetition }\end{array}$} & \multirow{2}{*}{$\begin{array}{l}\text { Psychological } \\
\text { Visualization }\end{array}$} \\
\hline & & & Passive & Aerobic & Stretching & & \\
\hline Frank et al. [7] & Sport & S & $\sqrt{ }$ & $\sqrt{ }$ & $\sqrt{ }$ & $\sqrt{ }$ & $\sqrt{ }$ \\
\hline Smith $[16]$ & Sport & S & $\sqrt{ }$ & $\sqrt{ }$ & $\sqrt{ }$ & - & - \\
\hline Hedrick [4] & Sport & $S$ & $\sqrt{ }$ & $\sqrt{ }$ & - & $\sqrt{ }$ & $\sqrt{ }$ \\
\hline Knight [10] & Sport & $\mathrm{EX}$ & $\sqrt{ }$ & $\sqrt{ }$ & $\sqrt{ }$ & - & - \\
\hline Garrett et al. [20] & Sport & $S$ & - & $\sqrt{ }$ & $\sqrt{ }$ & - & - \\
\hline Thacker et al. [44] & Sport & $S$ & - & $\sqrt{ }$ & $\sqrt{ }$ & - & - \\
\hline Fadkin $[8]$ & Sport & $\mathrm{EX}$ & - & $\sqrt{ }$ & $\sqrt{ }$ & $\sqrt{ }$ & - \\
\hline Safran et al. [6] & Sport & S & $\sqrt{ }$ & $\sqrt{ }$ & $\sqrt{ }$ & $\sqrt{ }$ & - \\
\hline Frank et al. [7] & Sport & S & $\sqrt{ }$ & $\sqrt{ }$ & $\sqrt{ }$ & $\sqrt{ }$ & $\sqrt{ }$ \\
\hline Woods et al. [3] & Sport & S & $\sqrt{ }$ & $\sqrt{ }$ & $\sqrt{ }$ & $\sqrt{ }$ & - \\
\hline Neuberger [13] & Sport & S S & $\sqrt{ }$ & $\sqrt{ }$ & - & $\sqrt{ }$ & $\sqrt{ }$ \\
\hline Strome $[9]$ & Sport & $\mathrm{EX}$ & $\sqrt{ }$ & $\sqrt{ }$ & $\sqrt{ }$ & & \\
\hline Willford [12] & Sport & $\mathrm{EX}$ & - & $\sqrt{ }$ & $\sqrt{ }$ & - & - \\
\hline Karen [82] & Music & $\mathrm{O}$ & - & $\sqrt{ }$ & $\sqrt{ }$ & $\sqrt{ }$ & - \\
\hline Zaza [24] & Music & $\mathrm{O}$ & - & $\sim$ & $\sim$ & $\sqrt{ }$ & $\sqrt{ }$ \\
\hline Comeau $[88]$ & Music & $\mathrm{O}$ & - & - & $\sqrt{ }$ & $\sqrt{ }$ & $\sqrt{ }$ \\
\hline Norris [89] & Music & $\mathrm{O}$ & - & $\mathrm{X}$ & $\sqrt{ }$ & $\sqrt{ }$ & $\sqrt{ }$ \\
\hline Harrison [91] & Music & $\mathrm{O}$ & $\sqrt{ }$ & $\sqrt{ }$ & $\sqrt{ }$ & $\sqrt{ }$ & $\sqrt{ }$ \\
\hline Medeline [116] & Music & $\mathrm{O}$ & $\sqrt{ }$ & $\sqrt{ }$ & $\sqrt{ }$ & $\sqrt{ }$ & $\sqrt{ }$ \\
\hline
\end{tabular}




\subsubsection{Analyzing Passive Warm-Up and its Effects}

In passive warm-up the skin or required muscles are warmed by some external means, such as taking a hot shower, steam bath or wearing more clothes $[3, \tau, 11,9: 3]$. The effects of the passive warm-up are superficial. This can explain why the passive warm-up is usually used as a complementary method to the active warm-up [9]. As has been shown in Figure 5.1, passive warm-up has unfocused physiological effects on the human body. For example, an increase in body temperature, improves the muscle flexibility which may result in reducing the risk of injury [93]. Increasing the body temperature by some external means has been mentioned in the discipline of music [91]. In addition, in the informal survey of music students, students $\mathrm{E}$ and $\mathrm{H}$, for example, refers to its use. Neither the music literature, nor music students mentioned these preparations as parts of a predefined routine. Thus, as previously mentioned, these preparations are categorized into the nature of the passive warm-up usual in athletics.

As has been shown in Figure 5.2 and Table 5.1, a large fraction of athletes perform passive warm-up when compared to musicians. The athletic literature recommends performing the passive warm-up twice as often as the music literature. This could be related to the fact that the passive warm-up was not recognized as a form of warm-up in any of the papers in the discipline of music. A comparison between the opinions expressed in the music literature and the opinions of the music students shows that there is a close relationship between what the music literature advises musicians do in terms of preparation and what the music students report performing.

\subsubsection{Analyzing Active Warm-Up and its Effects}

As has been seen in Figure 5.1, active warm-up includes three components: exercising aerobically, stretching, and repeating movements that are similar to the actual event. Each of these components affects the human body and mind differently. As has been illustrated in Figure 5.1, the active warm-up has both unfocused and focused physiological effects in addition to focused psychological effects. Unfocused physiological effects result from performing aerobic exercise before the performance.

During aerobic exercise, the body temperature rises through the movement of major muscle groups. In this stage, an individual does not concentrate on warming up 
specific portions of the body which will be used in the subsequent event. The goal of this stage is to increase the general body temperature to trigger chemical and hormonal reactions within the body.

Stretching has focused physiological effects on the human body. In this stage, an individual concentrates on stretching the portions of the body that will be used in the subsequent event.

Repetition/related movements belongs to both active and specific warm-up because of its characteristics. This component has focused physiological and psychological effects on the human body. The focused physiological effects are because playing a piece of music is, in fact, performing a task physically. In this stage, an individual concentrates on specific portions of the body. This repetition/related movements in specific portions of the body, enhances the nervous system of the individual, making it part of the specific warm-up. In addition, playing a piece similar to the actual piece, makes the individual mentally ready for the performance by increasing the confidence level. Therefore, this component of active warm-up has neuromuscular effects on the individual and is, therefore based on gathered information, an important part of a musician's warm-up.

Figure 5.3 shows a comparison of different components of active warm-up as expressed by opinions presented both in the athletics literature and the music literature. As is shown in Figure 5.3, aerobic exercise is a frequent component of active warm-up in the discipline of athletics. On the other hand, aerobic exercise is not a typical component of active warm-up in the discipline of music. In 1994 Zaza [24] stated that physical warm-up before the performance might be beneficial for musicians, but that more research was required to prove if that was the case. Sixteen years later, in 2010, she and her colleague [113] stated that physical warm-up should be a part of the warm-up in the discipline of music. Even so, Zaza $[24,113]$ does not clearly define physical warm-up. Similarly, the recommended duration and the intensity of the warm-up have rarely been discussed in the available literature.

Figure 5.4 shows a comparison of different components of active warm-up between the opinions expressed in the music literature and those of the music students. As 


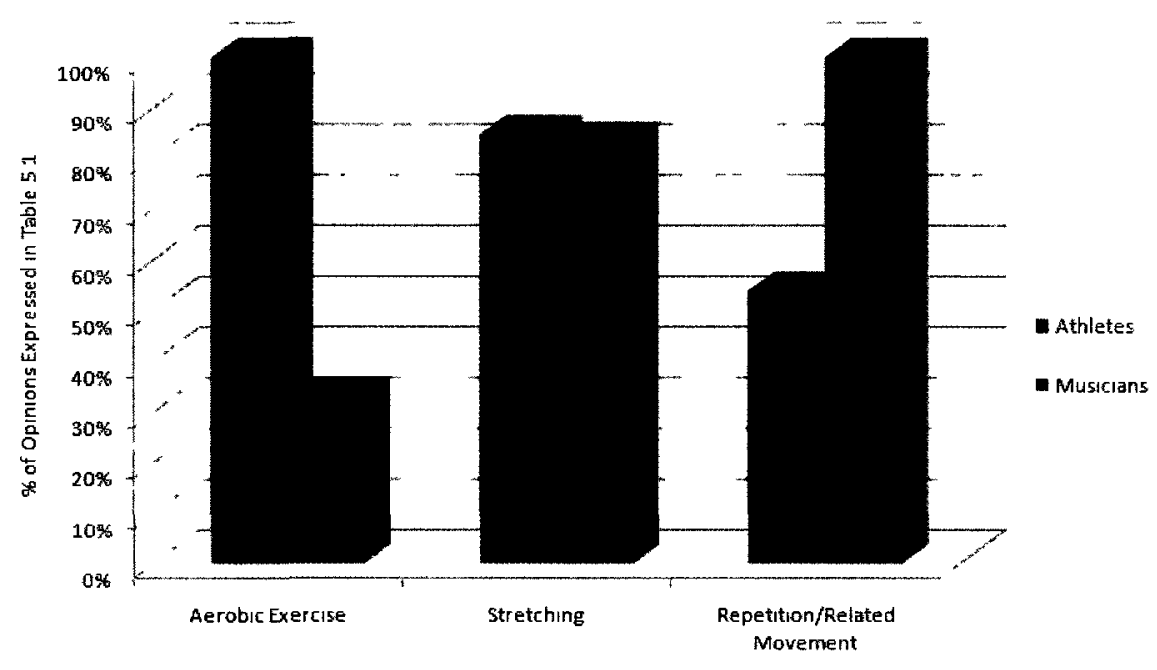

Figure 5.3: Comparison of Different Components of the Active Warm-Up in Athletes and Musicians

shown in Figure 5.4, there is a difference of opinions on performing aerobic exercise as a part of active warm-up. None of the music students included aerobic exercise as a part of their preparation. On the other hand, the music literature indicates that performing physical activity before playing could be beneficial $[21,91,11: 3]$. Stretching is a common component of active warm-up according to the opinions expressed in the music literature and music students. The music students believed that stretching reduces the chance of injury and improves the performance because it increases the muscle flexibility. It is necessary to mention that the positive attitude that music students have toward stretching could be as beneficial as the positive effects of stretching. Related movement is an important component of the warm-up in the discipline of music according to the opinions expressed in the literature. This was supported by the informal survey of music students in which all the music students reported performing this form of musical preparation before a performance.

\subsubsection{Analyzing Specific Warm-Up and its Effects}

Specific warm-up is a special type of warm-up because an individual is free to choose the piece of music that improves concentration. The music students performed this type of warm-up in different ways that helped them to concentrate and feel relaxed. 


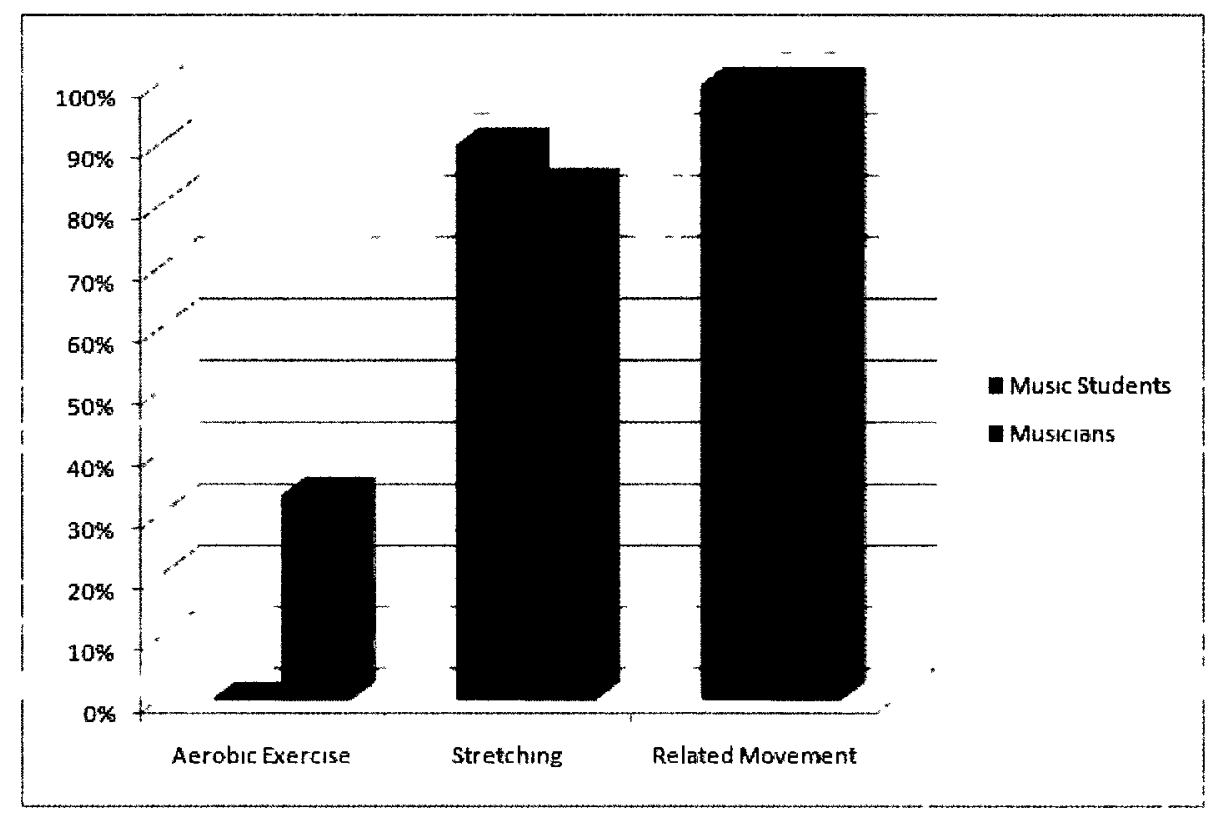

Figure 5.4: Comparison of Different Components of the Active Warm-Up in Musicians and Music Students

For example, student $\mathrm{C}$ chose a familiar piece for this part of warm-up. On the other hand, student D added some notes to well-known piece that she knew. As has been shown in Figure 5.1, specific warm-up is composed of two parts: repetition/related movements and visualization. The effects of repetition/related movements were discussed in the section on active warm-up. Visualization has focused psychological effects on the human body. Visualization helps an individual to gain confidence and also to reduce the chance of making errors by repetitive review in the mind. The importance of visualization is mentioned in athletics. In terms of the importance of psychological preparation, Massey [13] mentioned that if an individual performs physical warm-up and then is hypnotized to forget the physical preparation, the body acts as if the individual had never done the physical preparation. It does not appear that this type of experiment has ever been done in the discipline of music to see if there are similar results.

Figure 5.5 shows a comparison of specific warm-up based on the opinions expressed in the athletics literature and the music literature. As is shown in Figure 5.5, the music literature emphasizes the importance of performing the specific warm-up more often than does the athletics literature. This emphasis and the point that specific 


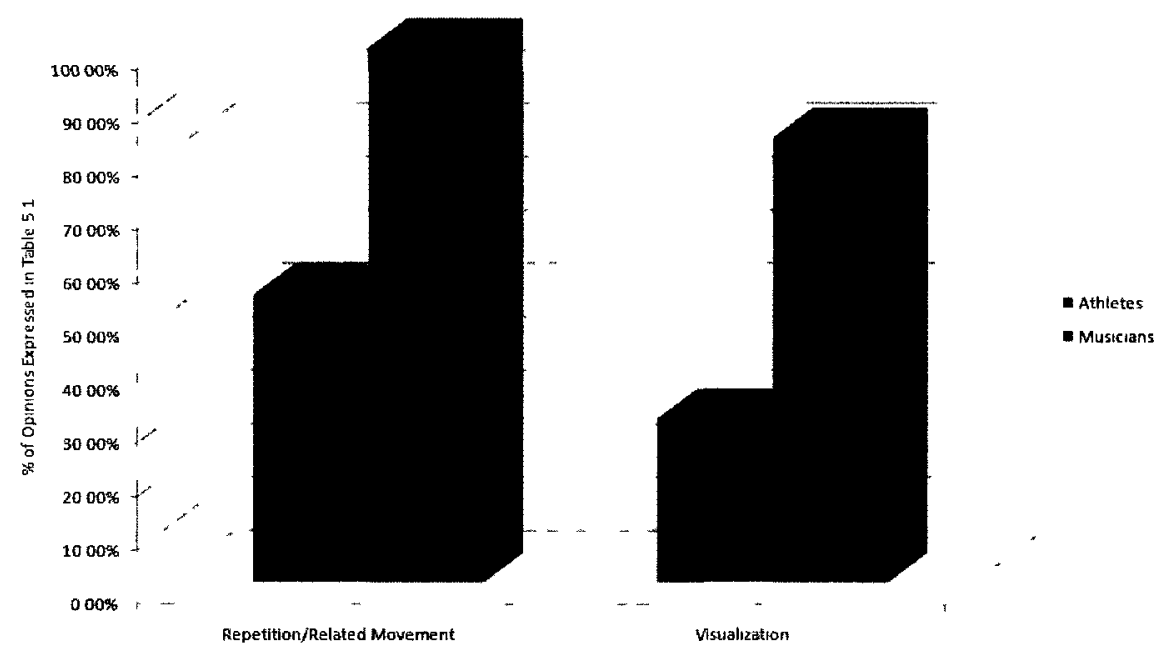

Figure 5.5: Comparison of Different Components of the Specific Warm-Up in Athletes and Musicians

warm-up is the safest type of warm-up [24], demonstrates that the specific warm-up should be a recommended component of a musician's warm-up. On the other hand, based on opinions expressed in the athletics literature, the specific warm-up is not considered as the most necessary component of the warm-up.

Figure 5.6 shows a comparison of opinions on the use of specific warm-up expressed in the music literature and by the music students. As has been shown in Figure 5.6, there are some similarities in both components of the warm-up between opinions expressed in the music literature and the music students. For example, as is shown in Figure 5.6, repetition/related movements is a necessary component from the perspective of both groups.

\subsection{Synthesizing the Role of Warm-Up in Injury Prevention}

In the second part of this chapter the role of warm-up in injury prevention based on quantification found in the available literature, is presented. There are several 


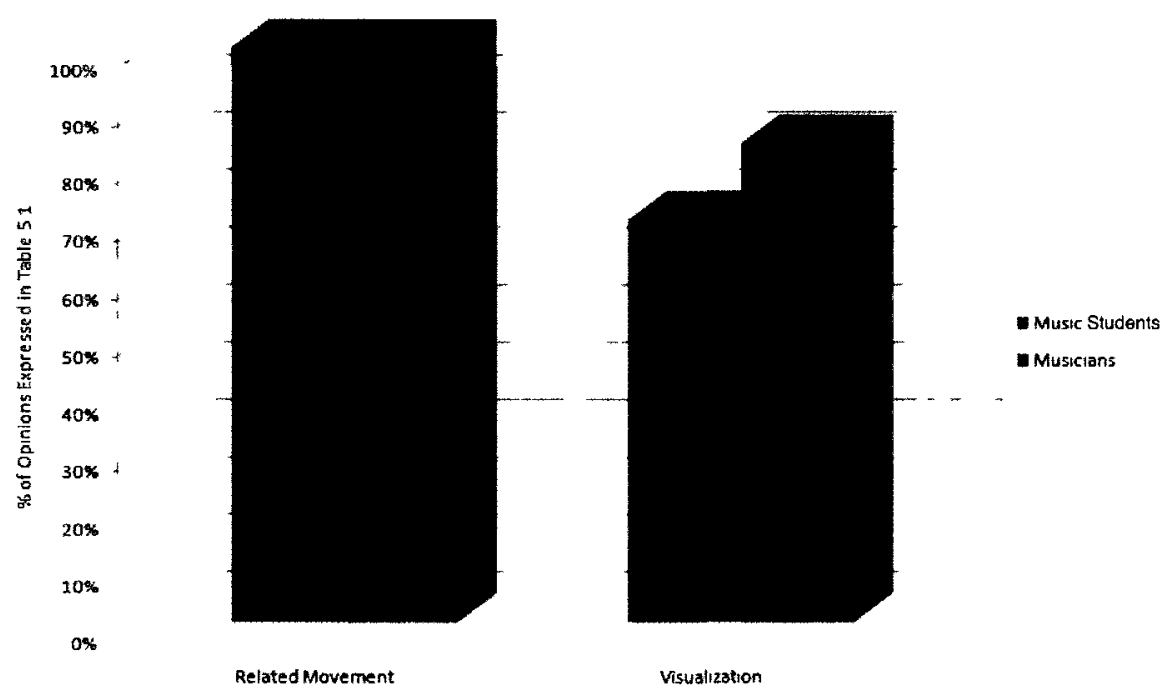

Figure 5.6: Comparison of Different Components of the Specific Warm-Up in Musicians and Music Students

factors involved in making the warm-up routine beneficial, neutral or harmful. These factors and their effects on the human body are described below.

\subsubsection{Analyzing Factors Involved in Warm-Up}

Neuberger [13] presented the hypothesis that the reason that some articles refute the benefits of warm-up is that the warm-up routine they applied was not performed with the right intensity and duration. As described in detail in Chapter 2, if an individual applies the warm-up routine with the right intensity and the duration, the body temperature rises. As a result of that, all the temperature-dependent reactions happen within the human body. In contrast, if an individual applies a superficial warm-up, the body temperature does not rise to the level required to trigger chemical and hormonal reactions. Finally, if an individual's warm-up is too intense, fatigue may result, rendering the person unable to perform properly [20]. Therefore, the right intensity and duration of warm-up are critical factors that are capable of changing the effects of the warm-up on the human body.

In athletics, the intensity and duration of the warm-up routine are related to the physical condition of an individual [3]. In music, the duration of the warm-up depends 
on the experience of an individual. An experienced person needs less time to be prepared for the event, compared to less experienced person [95]. This is a interesting comparison between these two disciplines, since the intensity and duration of warmup for athletes depend on how strong they are. In comparison for musicians, intensity and duration depend on expertise. There are general guidelines for the intensity and the duration of the warm-up routine in both disciplines, however neither the athletics literature nor the music literature gives clear guidelines on the intensity of the warmup and its duration.

The attitude of an individual toward the warm-up routine has been mentioned as an important factor in the discipline of athletics [13]. Taking breaks during the warmup session has only been mentioned in the discipline of music where music literature indicated that music students are encouraged to take breaks during a warm-up. This is thaught to prevent fatigue, overuse and stiffness of muscles [24,82]. Table 5.2 shows different factors reported to be involved in the warm-up routine in both disciplines.

Table 5.2: Effective Factors on Warm-Up Routine

\begin{tabular}{lcc}
\hline & Athletes & Musicians \\
\hline Attitude & $\sqrt{ }$ & $\mathrm{X}$ \\
Intensity & $\sqrt{ }$ & $\sqrt{ }$ \\
Duration & $\sqrt{ }$ & $\sqrt{ }$ \\
Breaks & $\mathrm{X}$ & $\sqrt{ }$ \\
\hline
\end{tabular}

\subsubsection{Perspective of Athletes}

Improper warm-up, excessive warm-up or no warm-up at all, as well as incorrect stretching techniques have been mentioned as factors that could lead to muscular injury among athletes $[6,75]$. There are numerous studies in the discipline of athletics, investigating effects of a warm-up and stretching on the human body. Table 5.3 presents a collection of four surveys, including of a total of 948 volunteers, on the effects of warm-up on injury prevention. This provides a view of warm-up from the perspective of the athlete. 
Table 5.3: Warm-Up and Injury Prevention from Perspective of Athletes (ROM indicates Range of Motion)

\begin{tabular}{|c|c|c|c|c|}
\hline Paper & Subjects & Warm-Up Time & Types of Warm-Up & Results \\
\hline Ekstrand et al [18] & 180 & $\begin{array}{l}20 \text { min warm-up } \\
10 \text { min stretching }\end{array}$ & NA & $\begin{array}{l}\text { Test group had } 25 \% \\
\text { fewer injuries } \\
\text { compared to control } \\
\text { group }\end{array}$ \\
\hline Knight $[10]$ & 97 & $\mathrm{NA}$ & $\begin{array}{l}\text { group1: Control group, no } \\
\text { stretching } \\
\text { group2: static stretching } \\
\text { group3: active heel rise before } \\
\text { stretching } \\
\text { group4: } 15 \text { min superficial moist } \\
\text { heat before stretching } \\
\text { group5: continuous ultrasound } \\
\text { for } 7 \text { min before stretching }\end{array}$ & $\begin{array}{l}\text { All group increase } \\
\text { ROM, group } 5 \text { is the } \\
\text { most effective for } \\
\text { improvement in ROM }\end{array}$ \\
\hline Bixler $[117]$ & 55 & $\begin{array}{l}\text { 1) } 3 \text { min warm-up/ } \\
\text { stretch ( } 3 \text { teams) } \\
\text { 2) controls ( } 2 \text { teams) }\end{array}$ & NA & $\begin{array}{l}\text { Fewer injuries in the } \\
3 \text { teams that } \\
\text { performed warm-up } \\
\text { and stretching }\end{array}$ \\
\hline Cross $[118]$ & 195 & $\begin{array}{l}\text { 1) static stretching } \\
\text { prior to conditioning } \\
\text { training } \\
\text { 2) no stretching } \\
\text { program }\end{array}$ & $\mathrm{NA}$ & $\begin{array}{l}\text { Static stretching } \\
\text { group has fewer } \\
\text { playing-related } \\
\text { injuries }\end{array}$ \\
\hline Van Mechelen [51] & 421 & $\begin{array}{l}19 \text { min warm-up: } 6 \\
\text { min running, } 3 \text { min } \\
\text { loosening, } 10 \text { min } \\
\text { stretching }\end{array}$ & NA & $\begin{array}{l}\text { Warm-Up is not } \\
\text { effective in reducing } \\
\text { injury }\end{array}$ \\
\hline
\end{tabular}


As mentioned earlier, warm-up in the discipline of athletics is well understood and it appears that there is a general agreement about its benefits. Therefore, most of the experiments in this discipline, are either investigating the effects of different types of stretching or investigating the effects of a combining different types of warm-up and stretching. As is shown in Table 5.4, most references agree that performing a warmup routine reduces the chance of injury. Nevertheless, some studies, such as [119] mentioned that performing a warm-up is not beneficial in preventing injury. As is shown in Table 5.4, Ekstrand [48] stated that warm-up and stretching together reduce the risk of injury. The reason that some articles refute the benefits of warm-up in injury reduction in the discipline of athletics may be associated with uncertainty in the definition of the physiological variables that they use as criteria. Nevertheless, these types of arguments are not linked with the warm-up defined for musicians, since the level of intensity and the duration are lower in musicians, which makes sense since physical effort is lower.

\subsubsection{Perspective of Musicians}

The importance of warm-up in injury prevention has been examined in three surveys, including among 499 music students $[112,111,120]$. Table 5.5 shows opinions, on the perspective, of those students about the importance of warm-up. As is shown in Table 5.5, music students performed physical and musical warm-up before the performance. They allocated some time to perform physical warm-up, but it is not clear what they did during physical warm-up. Warm-up and its components are rarely mentioned in the music literature and, when mentioned, the details regarding its definition and its components remain unclear.

\subsubsection{Perspective of Music Teachers}

Many playing-related injuries are linked to poor practice habits [113]. Therefore, teaching music students safe practice habits is essential. This emphasizes the critical role of music teachers in injury prevention [113]. Evidence shows that many music teachers learn about injury prevention strategies through other teachers, workshops, and conferences $[1,113]$. Attending these workshops and meeting with other music teachers can help them to update their knowledge and reduce the risk of injury among 
Table 5.4: Risk Factors in Injury Development from Perspective of 63 Music Teachers $[2 \overline{7}]$

\begin{tabular}{ll}
\hline Poor Physical Condition & $57.0 \%$ \\
Emotional Stress & $83.8 \%$ \\
Rapid Repetitive Movements & $75.4 \%$ \\
Poor Posture & $88.9 \%$ \\
Improper Techniques & $98.4 \%$ \\
Improper Instrument size & $44.6 \%$ \\
Too Much Practice & $69.3 \%$ \\
Not Enough Practice & $44.2 \%$ \\
\hline
\end{tabular}

their music students.

Music teachers and athletic coaches have many differences, but there is one difference that stands out among others. Athletic coaches know how injuries happen and how to reduce their likelihood. On the other hand, injuries and prevention strategies among music teachers are not as well known as they are among athletics coaches [구] Music teachers should be able to recognize different types of injuries and be knowledgeable about prevention strategies, since they may face an injured student in their class. They have to be able to teach their students proper playing techniques, and efficient position to reduce the risk of injury. They also should be prepared to advise their injured students with basic principles of injury management and alternative practice methods [27].

\subsubsection{Quantification of the Opinions Expressed by Music Teachers on the Causes of Playing-related Injuries}

There are 2 available surveys on the opinions of music teachers on injuries among musicians $[1,27]$. In [27], 63 music teachers presented their ideas about the factors leading to injury development among musicians. Opinions of music teachers [27] on common factors in developing injuries are presented in Table 5.4. 
Table 5.5: Warm-Up and Injury Prevention from Perspective of Music Students. [N is the number of subjects, $N_{W}$ is the number of subjects that warmed up, $X_{W}$ is the fraction of the subjects (in \%) that warmed up. ${ }^{*}$ It is not clear how many of students performed warm-up routine. It is indicated that $43.7 \%$ of the time, they warm-up prior to playing. $\nmid$ The time frame is between $0-60$ minutes.]

\begin{tabular}{|c|c|c|c|c|c|c|c|c|c|}
\hline & & & & & & & Type of W & arm-Up & \\
\hline & & & & & & Physiolog & cal & Combined & Psychological \\
\hline Paper & $\mathbf{N}$ & Gender & $N_{W}$ & $\boldsymbol{X}_{W}$ & Passive & Aerobic & Stretching & $\begin{array}{l}\text { Related } \\
\text { Movement }\end{array}$ & Visualization \\
\hline Yoshimura [114] & 35 & $\begin{array}{l}27 \text { female } \\
8 \text { male }\end{array}$ & NA & $43.7 \%^{*}$ & NA & 3.26 & $\min \dagger$ & $17.71 \min \dagger$ & $2.03 \min \dagger$ \\
\hline Yeung [112] & 39 & $\begin{array}{l}9 \text { female } \\
30 \text { male }\end{array}$ & 30 & $76 \%$ & & NA & & NA & $\mathrm{NA}$ \\
\hline Shoup [120] & 425 & $\begin{array}{l}276 \text { female } \\
149 \text { male }\end{array}$ & 338 & $79.5 \%$ & $5.70 \%$ & $63.10 \%$ & $15.50 \%$ & $24.50 \%$ & $\mathrm{NA}$ \\
\hline
\end{tabular}


As shown in Table 5.4, poor physical condition is mentioned as one of the factors that may lead to the development of injury. This supports the integrity of the developed framework for definition of the warm-up, in particular the requirement for aerobic exercise and stretching as two components of the active warm-up. Performing these two components of the active warm-up can contribute to the improvement of physical conditioning. Moreover, emotional stress is mentioned as another factor that may lead to injury. The specific warm-up, which is mentioned as one of the warm-up types in the framework previously defined, is composed of related movements and visualization. Related movement enhances the nervous system of an individual and visualization improves the confidence level. Therefore, these two components of the specific warm-up can contribute to reduction in emotional stress.

A survey of 42 music teachers indicated that they allocate some time in each session to talk about the importance of injury prevention [1]. Table 5.6 shows the time allocated to injury prevention in a 30 minutes session.

Table 5.6: Time Spent by Music Teachers on Injury Prevention in a Lesson

\begin{tabular}{cc}
\hline Time in minute & $\%$ of Teachers \\
\hline $0-5$ & $68 \%$ \\
$6-10$ & $24 \%$ \\
$11-15$ & $3 \%$ \\
$26-30$ & $5 \%$ \\
\hline
\end{tabular}

Table 5.6 confirms the importance of injury prevention from the perspective of music teachers. It is important to understand injury prevention strategies in order to reduce the risk of injury. The risk factors listed in Table 5.4 support the idea that performing physiological and psychological warm-up based on the developed framework for definition of warm-up may lead to reducing the risk of injury in musicians. 


\subsubsection{Injury Prevention Strategies Expressed by Music Teachers}

The literature gives general recommendations on how and when a musician should practice or play in order to reduce the risk of injury; e.g., $[81,113]$ :

- a musician should never practice when his/her hands are cold,

- a musician should have warm-up and cool-down exercises before and after each session,

- a musician should never play through pain,

- a musician should never increase the practice time suddenly.

A survey of 42 music teachers [1] presented a list of prevention strategies. Teachers mentioned they are informed about these prevention strategies by talking to each other, going to workshops, taking courses, reading books, and in consultation with medical practitioners [i]. Table 5.7 shows these prevention strategies.

As shown in Table 5.T, warm-up is mentioned as one of the factors that can lead to injury prevention, but the type of warm-up and the duration of warm-up have not been mentioned. Strengthening and flexibility exercise are mentioned as strategies for injury prevention. This supports the author's developed framework which includes stretching to increase flexibility. In addition, relaxation techniques and stress reduction are also mentioned as two prevention strategies. These fit into the definition of the specific warm-up, as included in the developed framework. Cognitive rehearsal or visualization, is mentioned as another prevention strategy. Visualization is part of the specific warm-up in the developed framework. Using heat is mentioned as a prevention strategy and this is a type of passive warm-up in the proposed definition.

\subsubsection{Common Treatments Offered by Music Teachers}

Musicians often prefer to treat their injuries by themselves, without going to clinical care centers or mentioning their injury to anyone. Unfortunately, they often seek professional care when an injury is advanced and is harder to treat and sometimes, it takes longer to recover. This ignorance of injury may be due to the pressure of employment and the risk of revealing past injuries. 
Table 5.7: Injury Prevention Strategies from Perspective of 42 Music Teachers [1]

\begin{tabular}{lc}
\hline Methods & \% of Teachers \\
\hline Proper Playing Techniques & $76 \%$ \\
Proper Body Mechanisms and Body Postures & $76 \%$ \\
Importance of Warm-UP & $64 \%$ \\
Risk Factors Associated with Overuse Injuries & $60 \%$ \\
Basic Anatomy & $60 \%$ \\
Importance of Strengthening and Conditioning & $57 \%$ \\
Specific Stretching and Flexibility Exercise & $57 \%$ \\
Relaxation Techniques & $55 \%$ \\
Cognitive Rehearsal (Visualization) & $55 \%$ \\
Importance of Taking Breaks & $50 \%$ \\
Awareness of Physical Limitations & $50 \%$ \\
Practicing When Refreshed and Unfatigued & $50 \%$ \\
Use of Heat or Cold for Treatment of Injury/Pain & $50 \%$ \\
Increasing Practice Load Incrementally and Varying Practice Contents & $45 \%$ \\
Massage Techniques & $40 . \%$ \\
Stress Reduction & $36 \%$ \\
\hline
\end{tabular}


Music teachers should try to have a sufficient knowledge of their students to advise them on correct warm-up techniques, correct playing techniques, also to encourage them to take care of their injuries in early stages. In surveys of 105 music teachers [1, 27 ], teachers offered different treatments for injuries. Table 5.8 shows the treatments suggested by music teachers.

As is shown in Table 5.8, longer warm-up is mentioned as one of the treatments that music teachers suggest for their students. Stretching, which is one of the active warm-up components in the developed framework, is mentioned as another treatment strategy. Relaxation techniques are mentioned as another treatment by music teachers. Relaxation is achieved by performing specific warm-up, since the specific warm-up improves the confidence level. For example, by visualizing playing a piece of music before the event, the confident level increases and also the chance of making errors reduces.

Table 5.8: Treatments Offered by 105 Music Teachers

\begin{tabular}{lcc}
\hline Paper & Redmond and Tienan [1] & Quarrier [2-i] \\
\hline Take a Short Time Off & $59 \%$ & $80 \%$ \\
Relaxation Techniques & $37.5 \%$ & $70 \%$ \\
Stretching & $19 \%$ & $71 \%$ \\
Longer Warm-Up & $41 \%$ & $76 \%$ \\
Ice Application & $16 \%$ & $41 \%$ \\
Heat Application & $16 \%$ & $26 \%$ \\
Use of Medication & $6 \%$ & $70 \%$ \\
\hline
\end{tabular}

\subsection{Summary}

In this chapter, the author performed a synthesis analysis of the warm-up routines used in the disciplines of music and athletics and separated the different types of warm-up into categories based on their effects. 
Even though it might appear that athletes and musicians have little in common, there are many similarities in the way in which these two groups prepare themselves for performance. The discipline of music does not have a clear definition for warm-up. However, after reviewing the scattered information in this discipline and comparing it with the systematic framework for the definition of warm-up in the discipline of athletics, it is clear that musicians should follow in the footsteps of athletes when it comes to warm-up.

A novel framework fro the definition of warm-up including focused and unfocused physiological and focused psychological effects is developed in this chapter. This thesis reveals that musicians perform some types of warm-up before performance, although these preparations have rarely been quantified. In addition, aerobic exercise is not a typical type of warm-up in the discipline of music. Gathered data from the music students supports this assertion, since none of students performed aerobic exercise in their warm-up. Although it might seem unusual, performing aerobic exercise less strenuous than that of athletes, will be of benefit to musicians. For example, the heart rate increases after only a few minutes of light walking, leading to an increase in body temperature along with the corresponding hormonal and chemical changes provided by aerobic warm-up known to reduce the risk of injury and improve the quality of the performance. Stretching is the second component of the active warm-up. Musicians should apply this stage carefully. They should be careful not to pull muscles forcefully. The last stage of the active warm-up is repetition/related movement. This is a very important component for musicians, since it helps them to feel confident and reduces stress. 


\section{Chapter 6}

\section{Contributions}

\subsection{Discussion}

The goal of this study was to investigate effects of warm-up on reducing the risk of injury on musicians, especially pianists. There is little available literature in the discipline of music that investigates the physiological and psychological effects of the warm-up routine on musicians. Before performing extensive, time consuming and expensive experiments, the author investigated these effects in another discipline in which there is more information available about warm-up as an injury prevention strategy. From this a novel framework for definition of warm-up was developed. Specially, the framework for warm-up includes passive, active and specific components. In turn, the active component includes aerobic exercise, stretching and repetition/related movement.

This synthesis reveals that musicians already follow a warm-up routine, which approaches that of athletes. The principal difference is that warm-up is not clearly organized in the discipline of music. Musicians perform some types of warm-up without knowing that they are well-known types of warm-up in athletics. For example, musicians perform passive warm-up to increase flexibility, but it is not known or understood to be passive warm-up. However, what musicians do is exactly what athletes call passive warm-up.

More research is required to validate the integrity of the developed framework. As has been shown in figure 5.1, there are three types of warm-up routine: passive, active and specific. Passive warm-up is usually used as a complementary method 
to the active warm-up. Active warm-up is composed of three stages: light aerobic exercise, stretching and repetition/related movement. Aerobic exercise is not a wellknown component of active warm-up in the discipline of music. However, based on its benefits, it has been proposed to be a part of their preparation. Performing light aerobic exercise could be beneficial for musicians it triggers hormonal and chemical reactions within the body. The proposed aerobic exercise for musicians is different from that of athletes in that the intensity and duration of aerobic exercise are lower than for athletes. For example, several minutes of walking is considered an aerobic exercise provided an increase of body temperature of about $1^{\circ} \mathrm{C}$ is achieved.

Stretching and repetition/related movement are the other two components of the proposed active warm-up routine. These two components have long been part of the preparation of musicians. Musicians should be educated about stretching techniques to reduce the chance of injury. The final component of warm-up is repetition/related movement which belongs to both active and specific warm-up. This component has physiological and psychological effects on musicians. In this stage, a musician should take the required time to feel comfortable with the instrument and the piece of music.

Specific warm-up is the last type of proposed warm-up and it has two components: repetition/related movement and visualization. Visualization helps to improve confidence and reduces the risk of injury and is considered an effective type of warm-up for musicians.

\subsection{Recommendations}

The gathered information in the discipline of music reveals that participating in conferences and workshops helps music teachers to be up-to-date on prevention strategies, correct techniques and different injuries. They mentioned [27] that they become more knowledgeable through these conferences. Expanding these conferences to include more scientific education in terms of biomechanical knowledge to familiarize music teachers with different prevention strategies, such as warm-up is recommended.

One of the main concerns in the discipline of music is that peers teach each other incorrect techniques [24]. Students also may offer each other techniques that have been advised by their physiotherapist or their music teachers, but not all techniques 
work for everybody. Techniques for injury prevention differ, depending on the physical condition and injury history of the students involved.

A mandatory course for young musicians in which they are educated about injury prevention strategies, alternative playing techniques in case of an injury, correct posture and playing related injuries and their symptoms is recommended. This could help students to recognize injuries in early stages before it becomes a time-consuming and economic issue for the musician. For example, Zaza [121] stated that in a survey of 300 Canadian music students, $69 \%$ thought that they knew the definition of tendinitis, but only $29 \%$ were correct. In addition, music teachers should try to have a bond with students, so students feel close enough to inform their teacher of early signs of injuries.

In the proposed course for musicians, teaching the power of physiological preparation is necessary. Music students may believe that they do not need to waste their time on making their body ready for the performance [91]. It is necessary to educate them that a healthy and alert body functions better than a body that is not ready for the performance. In addition, the importance of visualization and getting ready to perform psychologically, is a topic that should be emphasized in the proposed course.

\subsection{Future Work}

In this research, a framework for the definition of warm-up has been established and a synthesis analysis of warm-up in athletes and musicians was performed. The framework can now be utilized as the basis of multiple experiments investigating effects of warm-up in injury prevention among musicians. Specially, the benefits of aerobic exercise should be assessed. The author recommends that a future study be designed to compare a group of musicians who perform aerobic exercise to a group of musicians who do not perform aerobic exercise. This will help to see the long term effects of applying aerobic exercise. Finally, while the beneficial effects of visualization have been proven in the discipline of athletes [22] the same cannot yet be said for musicians and an experiment similar to [22] is also recommended. 


\section{List of References}

[1] M. Redmond and A. Tienan, "Knowledge and practice of piano teachers in preventing playing-related injuries in high school students," Medical Problems of Performing Artısts, vol. 16-1, pp. 32-38, March 2001.

[2] NC, "Don't let arthritis come between you and your garden," Vistas, vol. 29-6, p. 16, June 2010.

[3] K. Woods, P. Bishop, and E. Jones, "Warm-up and stretching in the prevention of muscular injury," Sports Medicine, vol. 37-12, pp. 1089-1099, Nov 2007.

[4] A. Hedrick, "Physiological responses to warm up," National Strength and Conditıoning Journal, vol. 14-5, pp. 25-27, Nov 1992.

[5] E. Roetert and T. Ellenbecker, Complete Conditıonıng for Tennıs, p. 43. The United States Tennis Association Incorporated, 2007.

[6] M. Safran, A. Seaber, and J. Garrett, "Warm up and muscular injury prevention. an update," Sport Medicıne, vol. 8-4, pp. 239-249, Oct 1989.

[7] F. Shellock and E. William, "Warming up and stretching for improved physical performance and prevention of sport-related injuries," Sport Medıcine, vol. 2-4, pp. 267-278, July-Aug 1985.

[8] A. Fradkin, "Warm-up... does it reduce the risk of injury," Sports Medıcine, vol. 37-12, pp. 215-220, 2007.

[9] F. Ingjer and S. Stromme, "Effects of active, passive or no warm-up on the physiological response to heavy exercise," European Journal of Appleed Physiology, vol. 40, pp. 273-282, 1979.

[10] C. Knight, C. Rutledge, M. Cox, M. Acosta, and S. Hall, "Effect of superficial heat, deep heat, and active exercise warm up on the extensibility of the plantar flexors," Physical Therapy, vol. 81-6, pp. 1206-1214, June 2001.

[11] F. Shellock, "Physiological, psychological, and injury prevention aspects of warm-up," Natıonal Strength and Condıtıoning Assocıatıon, vol. 8-5, pp. 24-27, Oct 1986 .

[12] H. Williford, J. East, H. Furman, and L. Burry, "Evaluation of warm up for improvement in flexibility," Amerıcan Journal of Sports Medıcine, vol. 14, pp. 316 319, July 1986. 
[13] T. Neuberger, "What the research quarterly says about warm-up," African Journal of Health Education, Recreation, vol. 40-8, pp. 75-77, Oct 1969.

[14] D. Eygendaal, F. Rahussen, and R. Diercks, "Biomechanics of the elbow joint in tennis players and relation to pathology," Britısh Journal of Sports Medicine, vol. 41-11, pp. 820-823, July 2007.

[15] A. Nurmekivi and H. Lemberg, "Local muscular endurance in middle distance running," Modern Athlete and Coach, vol. 1, pp. 1-5, 2010.

[16] C. Smith, "The warm-up procedure: To stretch or not to stretch? a brief review," Journal of Orthopedıc and Sports Physıcal Therapy, vol. 19-1, pp. 1217, Jan 1994.

[17] D. Taylor, J. Dalton, A. Seaber, and W. Garrett, "Viscoelastic properties of muscle-tendon units. the biomechanical effects of stretching," American Journal of Sports Meducine, vol. 18-3, pp. 300-309, June 1990.

[18] S. Magnusson, E. Simonsen, P. Agaard, G. Gleim, M. McHugh, and M. Kjaer, "Viscoelastic response to repeated static stretching in the human hamstring muscle," Scandınavian Journal of Medıcıne 83 Scrence in Sports, vol. 5-6, pp. 342-347, Dec 1995.

[19] S. Magnusson, E. Simonsen, P. Agaard, and M. Kjaer, "Biomechanical response to repeated stretches in human hamstring muscle in vivo," American Journal of Sports Medıcıne, vol. 24-5, pp. 622-628, Sept 1996.

[20] W. Garrett, M. Safran, A. Seaber, R. Glisson, and B. Ribbeck, "Biomechanical comparision of stimulated and nonstimulated skeletal muscle pulled to failure," American Journal of Sports Medicıne, vol. 15-5, pp. 448-454, Sept 1987.

[21] T. Nanoon, T. Best, A. Sabear, and W. Garret, "Thermal effect on skeletal muscle behavior," American Journal of Sports Medıcıne, vol. 21-4, pp. 517522, July 1993.

[22] B. Massey, "Effect of warm-up exercise upon physical performance using hypnosis to control the psychological variable," Research Quarterly, vol. 32, pp. 63-71, 1961.

[23] I. Malareki, "Investigation on physiological justification of so-called warmingup," Acta Physiological Poland, vol. 5-4, pp. 543 546, 1954.

[24] C. Zaza, "Research-based prevention for musicians," Medıcal Problem of Performıng Artısts, vol. 9-1, pp. 3-7, March 1994.

[25] A. Bandura, Socıal foundatıon of thought and action: A socıal cognitive theory, p. 617. Englewood Cliffs, 1986.

[26] M. Shaw, "The bones and muscles used while playing piano keyboard." http://ezinearticles.com/ ?The-Bones-and-Muscles-Used-When-Playing-The-Piano-Keyboard\&id= 649717. Cited Oct. 12, 2011. 
[27] N. Quarrier, "Survey of music teachers: Perceptions about music-related injuries," Medical Problems of Performing Artısts, vol. 10-3, pp. 106-110, Sept 1995.

[28] J. Beaulieu, "Developing a stretching program," Physıcıan Sports Medıcıne, vol. 9-11, pp. 59-66, 1981.

[29] I. Shrier, "Does stretching improve performance? a systematic and critical review of the literature," Clinıcal Journal of Sports Medıcıne, vol. 14-5, pp. 267273, Sept 2004.

[30] J. Liebesman and E. Cafarelli, "Physiology of range of motion in human joints: A critical review," Revolutıon Physıology Rehabılıtatıon Medıcine, vol. 6, pp. 131-160, 1994.

[31] J. Church, M. Wiggins, E. Moode, and R. Crist, "Effect of warm-up and flexibility treatments on vertical jump performance," Journal of Strength and Conditroning Research, vol. 15-3, pp. 332-326, Aug 2001.

[32] T. Stricker, T. Malone, and W. Garrett, "The effects of passive warming on muscle injury," American Journal of Sports Medicine, vol. 18-2, pp. 141-145, March 1990.

[33] I. Carlile, "Effect of preliminary passive warming-up on swimming performance," Research Quarterly, vol. 27, pp. 143-51, 1956.

[34] D. Vries and A. Herbert, "Effects of various warm-up procedures on 100-yard times of competitive swimmers," the Associatıon for Health, Physical Education and Recreation, vol. 30, pp. 11-22, 1959.

[35] L. Merlino and U. Lawerence, "Influence of massage on jumping performance," Research Quarterly, vol. 30, pp. 66-74, 1959.

[36] S. Walter, L. Hart, J. MCIntosh, and J. Sutton, "The ontario cohort study of running-related injuries," Archives of International Medrcine, vol. 149-11, pp. 2561-2564, Nov 1989.

[37] MedicineNet, "Carpal tunnel." http://www.medterms.com/script/main/ art. asp?articlekey=2642. Cited Nov. 02, 2010.

[38] D. Lamb, "Androgens and exercise," Medicıne 83 Scrence in Spots 83 Exercıse, vol. 7-1, pp. 1-5, Spring 1975.

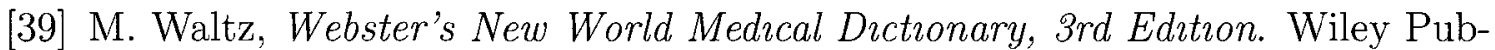
lishing, Inc, May 2009.

[40] B. Franks, "Athletics and cardiovascular health," Journal of Sports Medıcıne, vol. 3-4, pp. 172-178, July 1975.

[41] S.Gray, "Effects of active, passive or no warm-up on metabolism and performance during high-intensity exercise," Journal of Sports Scrence, vol. 19-9, pp. 693-700, Sept 2001. 


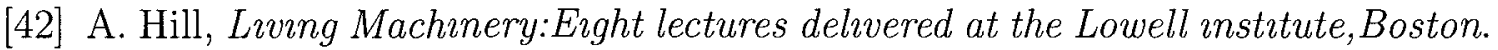
New York, Harcourt, Brace and Co, March 1927.

[43] G. Kenny, F. Reardon, W. Zaleski, M. Readon, F. Haman, and M. Ducharme, "Muscle temperature transients before, during, and after exercise measured using an intramuscular multi sensor probe," journal of applzed physiology, vol. 946. pp. 2350-2357, June 2003.

[44] S. Thacker, J. Gilchrist, D. Stroup, C. Dexter, and J. Kimsey, "The impact of stretching on sports injury risk: A systematic review of the literature," Medıcıne and Science in Sports and Exercuse, vol. 36-3, pp. 371-378, March 2004.

[45] M. Shaw, "Review of streching and warm-ups." http://www.topracket.com/ Badmintology/Research/Stretching.php. Cited Sept. 2, 2011.

[46] D. howell, "Musculoskeletal profile and incidence of musculoskeletal injuries in lightweight women rowers," American Journal of Sports Medicine, vol. 12-4, pp. 278-282, July 1984.

[47] D. Taylor, J. Dalton, A. Seaber, and W. Garrett, "Viscoelastic properties of muscle-tendon units. the biomechanical effects of stretching," Amerccan Journal of Sports Medrcine, vol. 18-3, pp. 300-309, June 1990.

[48] J. Ekstrand, J.Gillquist, and S.Liljedahl, "Prevention of soccer injuries: Supervision by doctor and physiotherapist," American Journal of Sports Medıcıne, vol. 11-3, pp. 116-120, June 1983.

[49] D. Rosenbaum and E. Hennig, "The influence of stretching and warm up exercises on achilles tendon reflex activity," Journal of Sport Scrence, vol. 13-6, pp. 481-490, Dec 1995.

[50] S. Jacobs and B. Berson, "Injuries to runners: A study of entrants to a 10,000 meter race," American Journal of Sports Medicine, vol. 14-2, pp. 151-155, March 1986.

[51] W. Mechelen, H. Hlobil, H. Kemper, W. Vooran, and H.DeJongh, "Prevention of running injuries by warm-up, cool-down, and stretching exercise," Amerccan Journal Sports Medicine, vol. 21-5, pp. 711-719, Sept 1993.

[52] M. Brunet, S. Cook, M. Brinker, and J. Dickinson, "A survey of running injuries in 1505 competitive and recreational runners," Journal of Sports Medrcine Physiology Fitness, vol. 30-3, pp. 307-315, Sept 1990.

[53] Online, "Passive stretching." http://www.mrfatloss.com/ pnf-stretching-is-active-as-well-as-passive-stretching. Cited Oct 10, 2011.

[54] Online, "Static stretching." http://www.musclesprod.com/bodybuilding/ bodybuilding-stretching-exercises-for-strength-training/. Cited Oct 10, 2011. 
[55] Online, "Isometric stretching." http://www.projectswole.com/ flexibility/what-is-isometric-stretching/. Cited Oct 10, 2011.

[56] Online, "Ballistic stretching." http://www.tryingfitness.com/ ballistic-stretching-dangerous-or-not/. Cited Oct 10, 2011.

[57] Online, "Pnf stretching." http://www.exrx.net/Stretches/Hamstrings/ PNFSeated.html. Cited Oct 10, 2011.

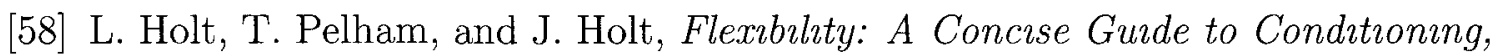
Performance Enhancement. 129: Humana Press., A part of Springer Science and Business Media. LLC, 2008.

[59] P. Schultz, "Flexibility: Day of the stretch," The Physıcıan and Sports Medrcine, vol. 7, pp. 109-117, 1979.

[60] J. Ciullo and B. Zarins, "Biomechanics of the musculotendinous unit: relation to athletic performance and injury," Journal of Clinıc and Sports Medicine, vol. 2-1, pp. 71-86, March 1983.

[61] J. Knapik, B. Jones, C. Bauman, and J. Harris, "Strength, flexibility and athletic injuries," Sports Medicine, vol. 14, pp. 277-288, 1992.

[62] J. Knapik, C. Bauman, and B. J. et al, "Preseason strength and flexibility imbalances associated with athletic injuries in female collegiate athletics," American Journal of Sports Medicine, vol. 19, pp. 76-81, 1991.

[63] J. Lee, B. Etnyre, H. Poindexter, D. Sokol, and T. Toon, "Flexibility characteristics of elite female and male volleyball players," Journal of Sports Medrcine Physical Fitness, vol. 29-1, pp. 49-51, March 1989.

[64] B. Jones and J. Knapik, "Physical training and exercise-related injuries. surveillance, research and injury prevention in military populations," Sports Medicine, vol. 27-2, pp. 111-125, Feb 1999.

[65] C. Hubley and J. Kozey, "Can stretching prevent athletics injury," Journal of Musculoskeletal Medicine, vol. 1-9, pp. 25-32, 1984.

[66] J. Davis and N. Epstein, "Mechanistic role of movement and strain sensitivity in muscle contraction," Proceedings of the Natıonal Academy of Scrences of the United States of America, vol. 106-15, pp. 6140-6145, April 2009.

[67] A. Sapega and T. Quedenfeld, "Biophysical factors in range of motion exercises," The Physicran and Sports Medrcine, vol. 9, pp. 57-65, 1981.

[68] E. Bressel and P. McNair, "Biomechanical behavior of the plantar flexor muscletendon unit after an achilles tendon rupture," The American Journal of Sports Medicine, vol. 29, pp. 321-326, May 2001.

[69] T. Noonan, T. Best, A. Seaber, and W. Garrett, "Thermal effects on skeletal muscle tensile behavior," The American Journal of Sports Medrcine, vol. 21-4, pp. 517-524, July 1993. 
[70] Online, "Sarcomeres." http://www.ccbm.jhu.edu/doc/courses/BME_ $580 \_682 /$ Computational $\% 20$ Models $\% 20$ of $\% 20$ the $\% 20$ Cardiac $\% 20$ Myocyte/ Lectures/Lecture $\% 201 \mathrm{~B} \% 20$ Structure $\% 20$ of $\% 20$ the $\% 20$ Myocyte/Lecture/ Lecture $\% 201 \mathrm{~B} \% 20$ Structure $\% 20$ of $\% 20$ the $\% 20$ Myocyte.htm. Cited Oct. 10 , 2011.

[71] G. Jacobson and E. Speechley, "Soccer warming up and stretching," South Africa Journal of Sports Medıcine, vol. 5-3, pp. 17-18, 1990.

[72] J. Smith and M. Bozymowski, "Effects of attitude toward warm-ups on motor performance," Research Quarterly, vol. 36, pp. 78-85, March 1965.

[73] M. Febbraio, M. Carey, R. Snow, C. Srathis, and M.Hargreaves, "Influence of elevated muscle temperature on metabolism during intense, dynamic exercise," American Journal of Physiology-Regulatory, Integratıve and Comparative Physiology, vol. 271-5, pp. 1251-1255, Nov 1996.

[74] C. Ethier and C. Simmons, Introductory Bıomechanıcs: From Cells to Organısms, pp. 332-337. Cambridge Texts in Biomedical Engineering, 2007.

[75] A. Fradkin, T. Zazryn, and J. Smoliga, "Effects of warming-up on physical performance: a systematic review with meta-analysis," Journal of Strength and conditioning Research, vol. 24-1, pp. 140-148, Sept 2009.

[76] W. Garrett, M. Safran, A. Seaber, R. Glisson, and B. Ribbeck, "Biomechanical comparison of stimulated and non-stimulated skeletal muscle pulled to failure," Sports Medicine, vol. 15-5, pp. 448-454, Sept 1987.

[77] J. Glick, "Muscle strains: Prevention and treatments," The Physıcıan and Sports Medicine, vol. 8-11, pp. 73-77, 1980.

[78] Online, "Cycle of muscle contraction." http://www.tutorvista.com/ biology/muscle-contraction-cycle. Cited Oct 10, 2011.

[79] H. DeVries, "Prevention of muscular distress after exercise," Research Quarterly for Exercuse \&3 Sport, vol. 32, pp. 177-185, 1961.

[80] T. Leyland, "Warm-up and cool-down." http://www.down-the-line.com/ warm-up-and-cool-down.html. Cited Jan. 21, 2011.

[81] B. Wristen, "avoiding piano-related injury: a proposed theoretical procedure for biomechanical analysis of piano technique," Medical Problems of Performing Artısts, vol. 15-2, pp. 55-58, June 2000.

[82] K. Frederickson, "Fit to play: Musicians' health tips," Music Educators Journal, vol. 88, pp. 38-44, May 2002.

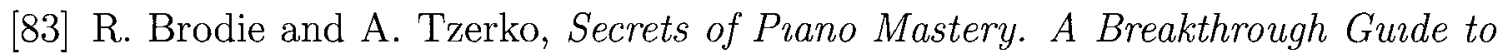
Pıano Technıque. 19.

[84] A. Watson, The Bıology of Musıcal Performance. 152: The Scarecrow Press,Inc, 2009. 
[85] M. Bruser, The Art of Practıcing, p. 29. Bell Tower, 1997.

[86] C. Vant, Driving point ımpedance measurements durıng pıano playıng, Master's Thesis. Ottawa: Carleton University, 2007.

[87] N. Sakai, "Hand pain attributed to overuse among professional pianist: a study of 200 cases," Medical Problems of Performıng Artısts, vol. 17-4, p. 178, Dec 2002.

[88] G. Comeau, "Warming up in piano playing: What does it really mean," in Two Day Workshop Symposium: Exploring the Physical and the Musical in Prano Technıque, pp. 55-58, March 2007.

[89] R. Norris, "Therapeutic exercise for musicians [videotape]. presented at the "playing less hurt"conference," Music Educator Journal, vol. 79,3, p. 10, 1992.

[90] B. Paull and C. Harrison, The Athletıc Musician, pp. 110-111. The Scarecrow Press,Inc, 1997.

[91] B. Paull and C. Harrison, The Athletıc Musıcıan. 134-142: The Scarecrow Press,Inc, 1997.

[92] M. Bruser, The Art of Practıcing, p. 46. Bell Tower, 1997.

[93] M. Bruser, The Art of Practıcing, pp. 32-34. Bell Tower, 1997.

[94] M. Bruser, The Art of Practıcıng, pp. 63-75. Bell Tower, 1997.

[95] M. Bruser, The Art of Practıcing, pp. 220-222. Bell Tower, 1997.

[96] D. Taubman, "The dorothy taubman seminar." http://www.taubmanseminar. com/index.html. Cited Nov. 21, 2009.

[97] M. Bruser, The Art of Practıcing, pp. 144-145. Bell Tower, 1997.

[98] R. Hoppmann and N. Patrone, "A review of musculoskeletal problems in instrumental musicians," Seminars in Arthritıs Rheumatzsm, vol. 19, pp. 117-126, 1989.

[99] C. Mason, J. Gomwz, and T. Ebner, "Hand synergies during reach-to-grasp," Journal of Neurophysiology, vol. 86-6, pp. 2896-2910, Dec 2001.

[100] T. Mark, "What every pianists need to know about the body." http:// pianomap.com/index.html. Cited Nov. 02, 2009.

[101] Online, "Carpal tunnel." http://www.medterms.com/script/main/art.asp? articlekey=2642. Cited Oct 10, 2011.

[102] J. Fry, "Overuse syndrome in musicians-100 years ago," The Medrcal Journal of Australia, vol. 145-11, pp. 620-625, Dec 1986.

[103] H. Blumenfeld, "Focal dystonia of the hand and what the brain has to do woth it." http://serendip.brynmawr.edu/exchange/node/1743. Cited Sept. 17, 2010. 
[104] Online, "Focal dystonia." http://www.orthosupersite.com/view.aspx?rid= 41046. Cited Oct 10, 2011.

[105] "Mediresource inc." http://bodyandhealth.canada.com/channel_ condition_info_details . asp?disease_id=229\&channel_id=42\%relation_ id=10900. Cited February 23, 2011.

[106] Online, "Tendonities." http://www.mywrist.info/topics/ type-of-wrist-problems/. Cited Oct 10, 2011.

[107] B. Paull and C. Harrison, The Athletıc Musıcıan, p. 151. The Scarecrow Press,Inc, 1997.

[108] Online, "Forearm stretching." http://www.womansday.com/Articles/ Health/Fitness-Exercise/Pain-Proof-Your-Body-Workout-Routine. html. Cited Oct. 30, 2011.

[109] Online, "Arm stretching." http://www.123rf.com/photo_3854273_ woman-at-the-gym-doing-arm-stretches-and-smiling.html. Cited Oct. 30, 2011.

[110] Online, "Back stretching." http://www.bernsteininstitute.com/ excercise_and_stretching.shtml. Cited Oct. 30, 2011.

[111] Online, "Neck stretching." http://arc4life.blogspot.com/2008/07/ pain-in-neck-causes-andy-roddick-to-sit.html. Cited Oct. 30, 2011.

[112] E. Yeung, W. Chan, F. Pan, P. Sau, M. Tsui, B. Yu, and C.Zaza, "A survey of playing-related musculoskeletal problems among professional orchestral musicians in hong kong," Medıcal Problems of Performıng Artısts, vol. 14-1, pp. 43-47, March 1999.

[113] C. Guptill and C.Zaza, "Injury prevention, what music teachers can do," Musıc Educators Journal, vol. 96-4, pp. 28-34, June 2010.

[114] E. Yoshimura, P. Paul, C. Aerts, and K. Chesky, "Risk factors for piano-related pain among college students," Medical Problems of Performing Artısts, vol. 213, pp. 118-125, Sept 2006.

[115] A. Watson, The Brology of Muscral Performance. xi-xv: The Scarecrow Press,Inc, 2009.

[116] M. Bruser, The Art of Practıcıng. Bell Tower, 1997.

[117] B. Bixler and R.Jones, "High-school football injuries: effects of a post-halftime warm-up and stretching routine," The Family Practıce Research Journal, vol. 12-2, pp. 131-139, June 1992.

[118] K. Cross and T. Worrell, "Effects of a static stretching program on the incidence of lower extremity musculotendinous strains.," The Journal of Athletıc Trainıng, vol. 34-1, pp. 11-14, Jan 1999. 
[119] G. Gleim, N. Stachenfeld, and J. Nicholas, "The influence of flexibility on the economy of walking and jogging," Journal of Orthopedrc Research, vol. 8-6, pp. 814-823, Nov 1990.

[120] D. Shoup, "Survey of performance-related problems among high school and junior high school musicians," Medıcal Problems of Performıng Artısts, vol. 103, pp. 100-105, Sept 1995.

[121] C. Zaza, "Playing-related health problems at a Canadian music school," Medrcal Problems of Performing Artısts, vol. 7-2, pp. 48-51, June 1992. 